\title{
Mechanical Performance of Mega Steel Frame-Prestressed Composite Bracing Structure
}

\author{
Tang Baijian, Shao Jianhua*, Pei Xingzhu and Gu Sheng
}

Department of Civil Engineering, Jiangsu University of Science and Technology, Zhenjiang, P.R.China 212003

\begin{abstract}
The mega structure has been widely studied and applied due to the clear force transferring way, good structural integrity and flexible layout of diverse building functions. Based on the structure of mega truss or mega frame, the research and application of the mega structure with many kinds of bracing structures become a hot topic in recent years. Mega steel frame-prestressed composite bracing structure with a rigid-flexible composite bracing system composed of rigid $\Lambda$-shape steel brace and inverted $\Lambda$-shape flexible cable is a new kind of mega structure and this composite bracing system is set up in the mega steel frame. By establishing the three-dimensional finite element model and considering the material and geometric nonlinearity, the structural performance under static load in whole process was analyzed and the energy dissipation as well as failure mode under earthquake is also investigated for this new system in this paper. The results indicate that the lateral deformation is mainly decided by horizontal load and the corresponding curve of lateral displacement has the characteristic of flexure mode as a whole, whereas the deflection of mega beam is mainly governed by vertical load and pretension of cables. The internal force equilibrium of composite brace is decided by vertical load and the degree of force unbalance is about $15 \%$ when the fluctuation of vertical load is $20 \%$, but the change of anti-symmetric horizontal load has no effect on the internal force equilibrium. The composite braces not only help the mega beam to bear the vertical load but also greatly enhance the lateral stiffness of main structure and so the lateral stiffness of whole system is relatively uniform. Due to the TMD effects of substructure and additional dampers, the seismic energy is mainly dissipated by dampers and substructure and then the main structure is able to maintain elastic. The desired failure mode of MFPCBS under lateral loads is as follows: the web members of mega beam appear to yield at first, and then the braces between mega column limbs, $\Lambda$-shape rigid bracing truss, floor beams between mega column limbs and mega column limbs in order.
\end{abstract}

Keywords: Steel structure, mega structure, prestress, composite brace, energy dissipation analysis.

\section{INTRODUCTION}

The concept of mega structure is derived from the 1960s. Due to many advantages such as the clear force transferring way, good structural integrity and the large lateral stiffness, the mega structure has been widely studied and applied since the first mega structure of Hancock Center in Chicago is built.

In 1990s, the active control of mega substructure under earthquake and wind load is investigated by Maria et al. [1, 2], which is the earliest control research for mega structure from the control view.

In 2004, Zhang [3] studied the space hysteretic behavior of mega steel column by pseudo-static loading test and modeled it using the theoretical model. This simulation achieved some promising results. Zhang's research will provide a basis for the mega steel column simplified to a single column and the large-scale numerical experiments.

*Address correspondence to this author at the Department of Civil Engineering, Jiangsu University of Science and Technology, Zhenjiang, P.R.China 212003; Tel: +86-511-84432200; Fax: +85-511-84402322;

E-mail: shaojianhua97@163.com
Zhang et al. [4] took the building of Tokyo city hall for example and analyzed the wind resisting performance of the mega-sub steel frame control system by means of the stochastic analysis method. The influence of stiffness ratio and mass ratio between the main structure and substructure on the control effect was especially studied.

Zhao [5] took the building of Shanghai world financial center as an example and studied the simplified model of the mega structure, especially of the beam-column joints. The elasto-plastic seismic performance of mega frame structure was preliminarily researched by applying Pushover analysis with the frequently used load mode.

Takabatake [6] took Tokyo New City Hall as an example and presented the practical method of elasto-plastic analysis on the mega steel frame through the equivalent model. The natural period of vibration, elastic response and static elastoplastic analysis for this structure were analyzed and then many satisfactory results were achieved.

Fan et al. [7] completely introduced the threedimensional finite element fine model, natural vibration characteristic, response spectrum analysis and seismic time history analysis of the Taipei 101 building which is the mega frame structure with concrete filled steel tubular. 
Kyoung [8] proposed a design method based on the structural stiffness for the mega truss so as to effectively determine the initial size of mega brace.

Zhou and Deng et al. [9] theoretically presented the mega frame-brace system and the mega frame- energy dissipation brace system to improve the lateral stiffness and seismic performance of mega frame structure. According to the numerical simulation and comparison of calculated results, the better static and dynamic performances were achieved for these new systems compared to the traditional mega structure. Lian et al. [10] studied the applications of frictional energy dissipation brace in the mega structure.

The first author [11] presents a new type of the mega steel frame-prestressed composite bracing structure with a rigid-flexible composite bracing system composed of rigid $\Lambda$-shape steel brace and inverted $\Lambda$-shape flexible cable. This composite bracing system is set up in the mega steel frame. The numerical example based on the actual project is adopted in this paper. According to the numerical analysis, the static performance of this new system is researched from the internal force and deformation view, the seismic performance is evaluated from the structural energy dissipation and the ultimate state is investigated from the desired failure modes.

\section{NUMERICAL EXAMPLE}

The computing model of the mega frame-prestressed composite bracing structure is shown in Figs. (1 and 2). The structure is diagonally symmetrical with square plan of 36 $\mathrm{m} \times 36 \mathrm{~m}$ (Fig. (1c)). The total height of the 54-storey frame structure is $216 \mathrm{~m}$ above the ground, and the height of each storey is $4 \mathrm{~m}$ [6]. There are four same $6 \mathrm{~m}$ square lattice mega columns at four corners. Each mega column consists of four box section columns through $\mathrm{K}$-shape brace connecting together. Mega beams are set to connect mega columns at Floor 9, 18, 27, 36, 45 and 54. Each mega beam is a onestorey height space truss including four I-section chords, several vertical and oblique web members. At the upper part

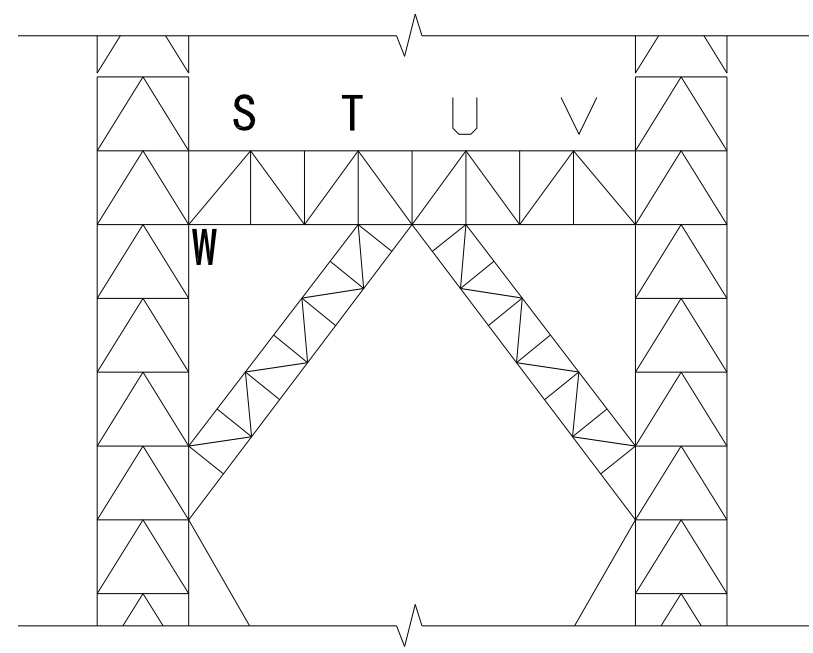

Fig. (2). Detail drawing of main members

of each mega storey, there is mega rigid $\Lambda$-shape brace having a same section as mega beam, and at the lower part there is inverted $\Lambda$-shape pre-stressed flexible cable (Fig. (1a)). On each mega storey, there are 8 crisscross plane trusses supporting on mega beams in order to suspend substructure. The damper is installed between the tail part of the suspended substructure and the main structure. Main member sizes are listed in Table $\mathbf{1}$.

In Fig. (1), the points $\mathrm{A}, \mathrm{D}, \mathrm{G}, \mathrm{J}, \mathrm{M}$ and $\mathrm{P}$ are the intersections of prestressed cable and lower chord of mega $\Lambda$-shape brace, as well as the inside limb of mega column. The point $\mathrm{C}, \mathrm{F}, \mathrm{I}, \mathrm{L}, \mathrm{O}$ and $\mathrm{R}$ are the intersections of lower chord of mega $\Lambda$-shape brace and mega beam. The point $\mathrm{B}$, $\mathrm{E}, \mathrm{H}, \mathrm{K}, \mathrm{N}$ and $\mathrm{Q}$ are the intersections of lower chord of mega beam and outside limb of mega column.

The diameter and initial prestress of every cable shown in Table $\mathbf{1}$ are determined according to the two principles: internal force equilibrium in composite bracings, and nonfailure of prestressed cables at any condition.

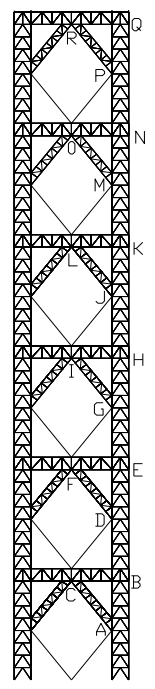

(a) Elevation view of main structure

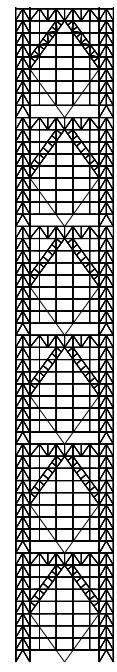

(b) Elevation view of main-sub-structure

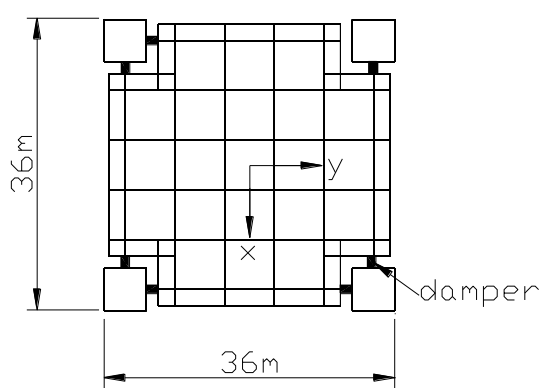

(c) Typical floor plan

Fig. (1). Steel mega frame and prestressed composite bracing structure. 
Table 1. Member size of MFPCBS.

\begin{tabular}{|c|c|c|c|c|c|}
\hline Member & Section Shape & $\mathbf{H} / \mathbf{m m}$ & $\mathrm{B} / \mathbf{m m}$ & $\mathbf{t}_{\mathbf{f}} / \mathbf{m m}$ & $\mathbf{t}_{\mathrm{w}} / \mathbf{m m}$ \\
\hline Limb of mega column(1st 2nd mega storey) & \multirow{2}{*}{ 口 } & 900 & 900 & 60 & 60 \\
\hline Limb of mega column(5th 6th mega storey) & & 900 & 900 & 20 & 20 \\
\hline K-shape brace of mega column & \multirow{6}{*}{$\mathrm{H}$} & 200 & 200 & 12 & 8 \\
\hline Chord of mega beam & & 1000 & 500 & 30 & 20 \\
\hline web member of mega beam & & 300 & 300 & 15 & 12 \\
\hline Chord of plane truss & & 400 & 200 & 12 & 8 \\
\hline web member of plane truss & & 300 & 300 & 15 & 12 \\
\hline vertical web member of mega $\Lambda$-shape brace & & 200 & 200 & 12 & 8 \\
\hline Hanging member(upper part) & \multirow{2}{*}{ 口 } & 250 & 250 & 10 & 10 \\
\hline Hanging member(lower part) & & 250 & 250 & 6 & 6 \\
\hline Beam of substructure & $\mathrm{H}$ & 350 & 200 & 11 & 7 \\
\hline Floor slab of substructure & \multirow{2}{*}{$\begin{array}{l}\text { Profiled sheet composite floor } \\
\text { (C30 concrete covered) }\end{array}$} & \multicolumn{4}{|c|}{$80 \mathrm{~mm}$ thickness } \\
\hline Floor slab of main structure & & \multicolumn{4}{|c|}{$80 \mathrm{~mm}$ thickness } \\
\hline inverted $\Lambda$-shape cable( 1 st mega storey) & $\circ$ & \multicolumn{4}{|c|}{ Diameter $344.1 \mathrm{~mm} /$ pre-stress $12304 \mathrm{kN}$} \\
\hline
\end{tabular}

Chinese Q345B is adopted in the material of all steel members, whose Young's modulus is $2.06 \times 10^{5} \mathrm{MPa}$ and the linear expansion coefficient $1.2 \times 10^{-5}$. The tensile strength of cables is $1470 \mathrm{MPa}$, whose Young's modulus is $1.40 \times 10^{5}$ $\mathrm{MPa}$ and the linear expansion coefficient is $1.59 \times 10^{-5}$.

\subsection{Load}

\subsubsection{Vertical Load V}

The dead load $D$ and live load $L$ of each mega storey are $6.0 \mathrm{kN} / \mathrm{m}^{2}$ and $2.5 \mathrm{kN} / \mathrm{m}^{2}$, respectively. The dead load $D$ and live load $L$ of each substructure storey are $4.5 \mathrm{kN} / \mathrm{m}^{2}$ and 2.5 $\mathrm{kN} / \mathrm{m}^{2}$, respectively. The basic composition of vertical load $V$ is equal to $D+0.5 L$ in this example.

\subsubsection{Wind Load $\mathrm{H}$}

Provided that the basic wind pressure $\omega_{0}=0.45 \mathrm{kN} / \mathrm{m}^{2}$. For convenience, the uniformly distributed wind load is adopted as a substitution for inverted triangular distribution wind load according to equivalence of bottom bending moment. The wind load of $7.38 \mathrm{kN} / \mathrm{m}$ is applied on the outside column limbs of mega columns with the right direction.

\subsubsection{Seismic Load E}

The seismic fortification intensity is 8 degree. The classification of design earthquake is group 1 , and the site classification is class II according to Chinese code.

The damping ratio $\xi$ is 0.02 if the structure is at the elastic stage, while the value will be calculated by the following formula [12] at the elasto-plastic stage:

$\xi=0.2 \times\left(1-\frac{1}{\sqrt{D_{f}}}\right)+0.02$

Where: $D_{f}$ is the plasticity ratio of structure [13], and

$D_{f}=\frac{\Delta_{s} \times Q_{d}}{\Delta_{d} \times Q_{s}}$ 
Where:

$\Delta_{d}$-the displacement representative value at the elastoplastic critical state

$\Delta_{s}$ - the displacement representative value at the plastic state $Q_{d}$ - the bottom shear force at the elasto-plastic critical state $Q_{s}$-the bottom shear force at the plastic state

The finite element program SAP2000 is used for analysis. The column element is adopted to simulate all members in mega beams, mega columns and mega bracings. The cable element is used for pre-stressed cables, the fournode shell element is applied to model floor plate and the link element is used for damper. The negative temperature method is adopted to apply the prestress [14, 15] and the material and geometry nonlinearity are considered in the calculation.

The sign of internal force is ruled by the followings in this paper. The pressure for the axial force of mega column and mega $\Lambda$-shape steel brace is positive, while the tension for the axial force of cable is positive. The tension at the outside limb for the moment of mega column is positive and the clockwise shear is positive. The tension at the lower chord for the moment of mega beam is positive and the counterclockwise shear is positive.

\section{STATIC ANALYSIS}

\subsection{Under Initial Prestress $P$}

\subsubsection{Structural Deformation}

As shown in Fig. (3), the deformation of each mega storey is very similar at the original prestressed state. The mega beam is upward convex and the maximum deflection at midpoint is $12.6 \mathrm{~mm}$ which is about $1 / 2300$ of the beam length. The mega column is inward concave. And the maximum displacement at midpoint is $15.8 \mathrm{~mm}$ which is about $1 / 1100$ of the column height.

\subsubsection{Internal Forces of Mega Column}

As shown in Fig. (4), the axial force of mega column is pressure except that column is located at the rigid $\Lambda$-shape brace segment at the top storey and this axial value changes suddenly at intersections of mega members. The maximum axial force occurs at the four bottom stories and is $4361 \mathrm{kN}$, which is equal to the vertical component of tension in the cable. The sign of shear force at the mega column alters at the intersection of rigid $\Lambda$-shape brace and prestressed cable, it can be explained by that the force transferred from the

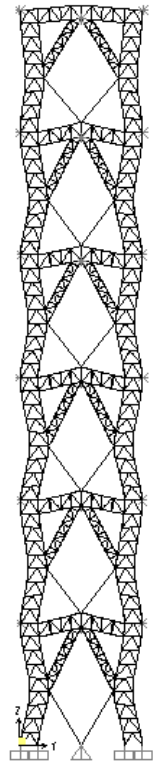

(a) Overall deformation

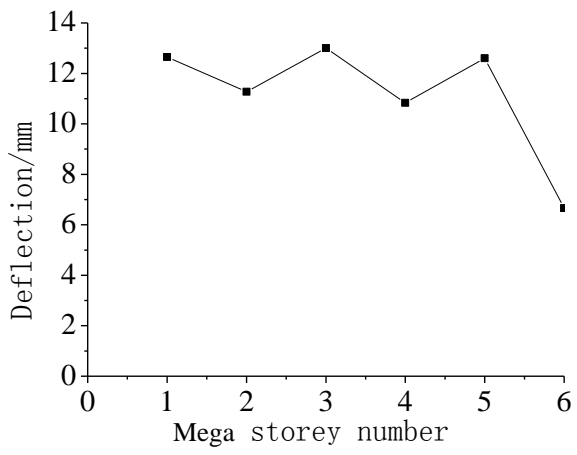

(b) Deflection at midpoint of mega beam

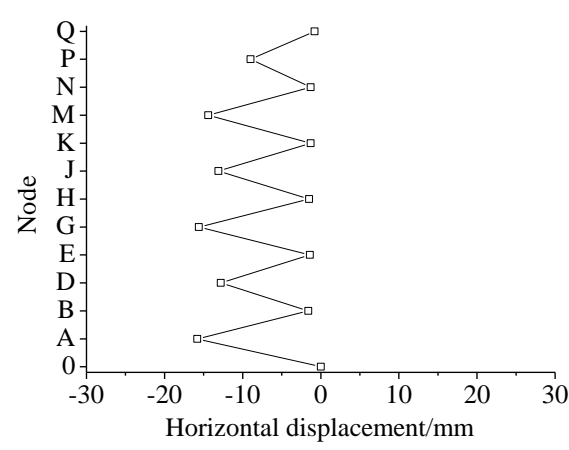

(c) Horizontal displacement of mega column

Fig. (3). Structural deformation at the prestress state.

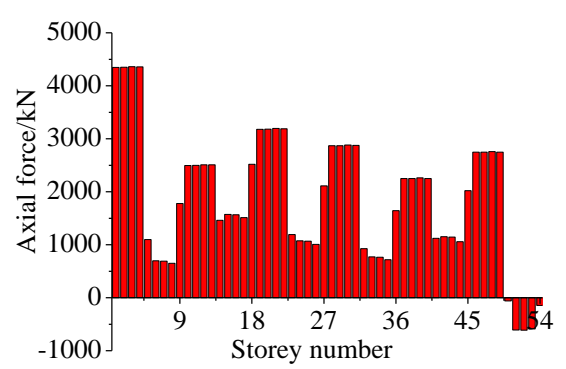

(a) Axial force

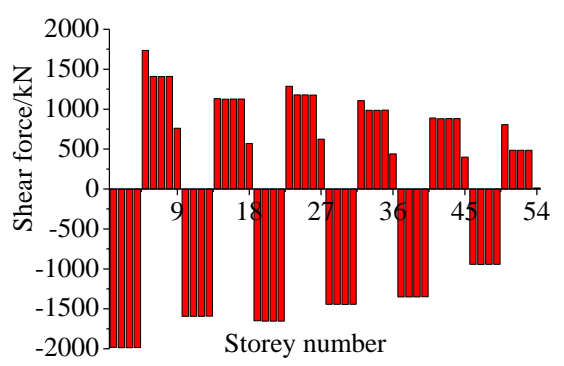

(b) Shear force

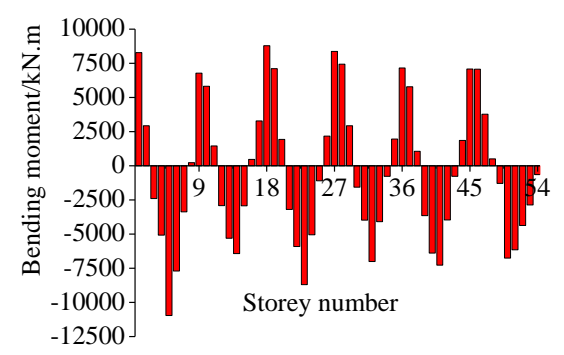

(c) Bending moment

Fig. (4). Internal forces in right-side mega column at the prestress state. 
cable is shared by the upper and lower part of mega column. The bending moment diagram of mega column is accordance with the overall deformation diagram of mega column at the prestressed state (Fig. (3a)). The maximum negative bending moment appears at the intersection of rigid $\Lambda$-shape brace and prestressed cable where the maximum concave deformation occurs, while the maximum positive bending moment occurs at the connection between mega beam and mega column.

\subsubsection{Internal Forces of Mega Beam}

As shown in Fig. (5), the maximum shear force and bending moment all appear at the midpoint of mega beam at the prestressed state, which is mainly because of the concentrated forces. The bending moment diagram coincides with the deformation of upward convex at the prestressed state (Fig. (3a)).

\subsubsection{Internal Force of Composite Bracing}

The sign of $c i$ represents cable at the i mega storey and $b i$ refers to the rigid brace at the i mega storey in Fig. (6). At the pure prestressed state, the internal forces of composite bracings are in disequilibrium, and the maximum difference occurring at bottom storey is nearly $6000 \mathrm{kN}$. The internal force of cable at each mega storey is tension and the rigid braces are compressed except at the top storey, however the compression is relatively small.

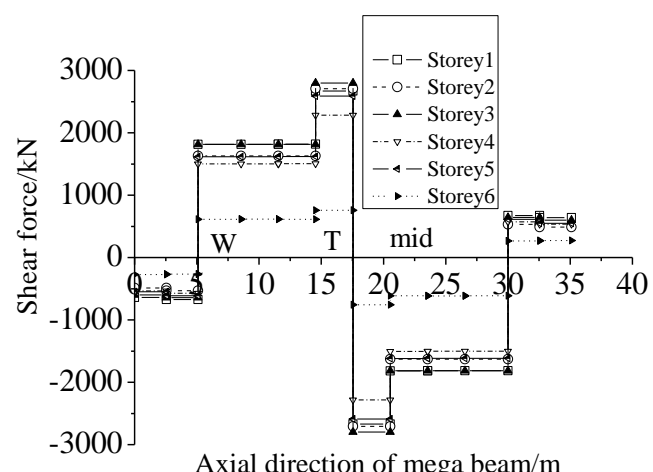

Axial direction of mega beam $/ \mathrm{m}$

(a) Shear force

\subsection{Under Prestress and Vertical Loads $P+V$}

\subsubsection{Structural Deformation}

As shown in Fig. (7), the mega column showed slightly inward concave deformation and the mega beam except at the top storey showed upward convex deformation under $P+V$. Since the prestress value in this example is determined according to internal force equilibrium in composite bracing under regular service, the above deformation characteristic has generality for mega frame and prestress bracing structure, which indicates that the pre-tension in cable can resist the compression caused by the vertical load and a small amount of surplus tension in cable is necessary to meet the reduction of tension induced by the following horizontal load.

The deformation diagram of each mega beam in $P+V$ condition is similar. Inverted arch appears at Storey 1 5, and the maximum deflection is about $7 \mathrm{~mm}$, which is close to the half value at the pure prestress state. Concave deformation appears at both end sections of the mega beam due to vertical loads. Inverted arch dose not appear at the top storey because there is not prestressed cables at that storey, but the trend of deformation is the same as that at the other storey.

Under $P+V$ condition, there is almost no horizontal displacement of mega column and the maximum drift displacement is only about $3 \mathrm{~mm}$. so it can be confirmed that the internal forces of composite bracings are in equilibrium

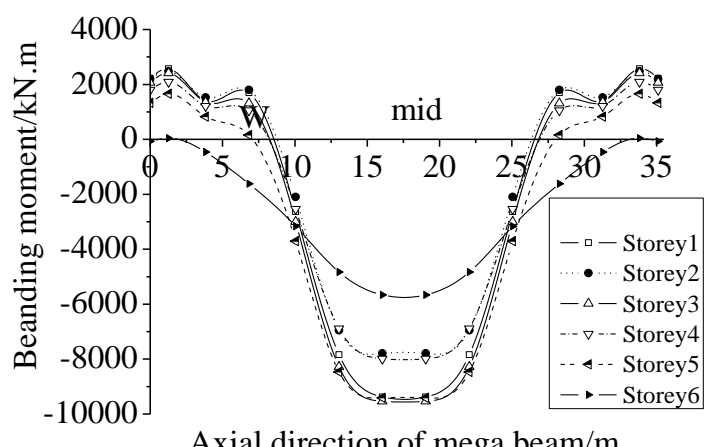

(b) Bending moment

Fig. (5). Internal forces of mega beam in prestress state.

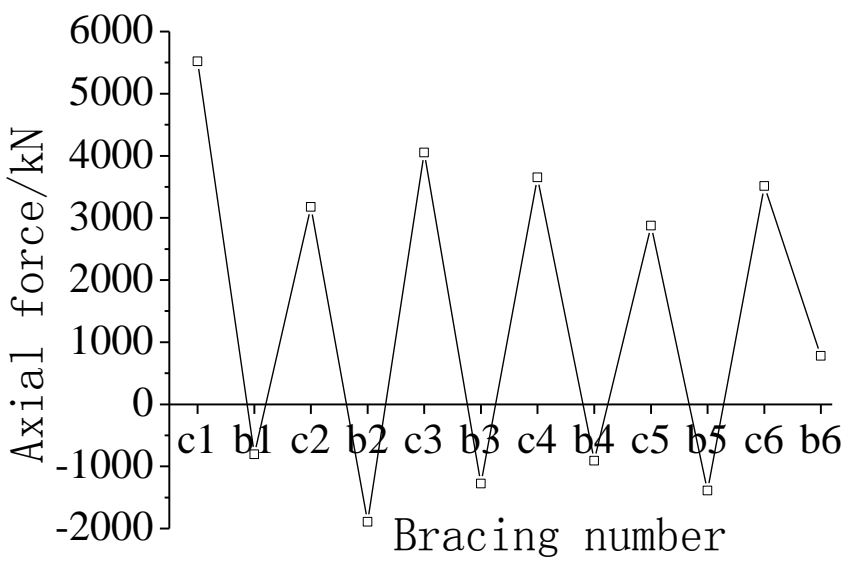

Fig. (6). Internal force of composite bracings at the prestress state. 
according to the deformation diagram.

\subsubsection{Internal Forces of Mega Column}

Under $P+V$ condition, the axial force diagram of mega column in Fig. (8) shows the stepped shape and the threshold position is the intersection of the rigid $\Lambda$-shape brace and the prestressed cable.

The shear force of mega column jumps drastically at intersections of mega members and the maximum value appearing at Storey 27 is $1321 \mathrm{kN}$. It should be pointed that the equilibrium of composite bracings in this example means that the total tension of cables is equal to the total axial compression of upper and lower chords in the rigid $\Lambda$-shape brace, and the internal force of web member of rigid brace is not taken into account, which results in jump of the shear force at the connection between chords of the rigid brace and mega column.
The bending moment of mega column at each mega storey changes periodically and it is negative in the rigid bracing segment except the bottom storey, while it is positive in the prestressed cable segment. The bending moment diagram shows the stepped shape, which reflects the transfer of the axial force in bilateral limbs of mega column. The maximum bending moment appears at four bottom stories. The bending moment turns direction at intersection of rigid brace and mega column, which is accordance with the deformation inflection point in Fig. (7a).

\subsubsection{Internal Forces of Mega Beam}

Comparing Fig. (9) with Fig. (5), the value of maximum shear force and bending moment at the mega beam midpoint under $P+V$ condition is less than that under the pure prestress condition because the increments of internal forces under vertical loads is opposite to those caused by prestressing, and

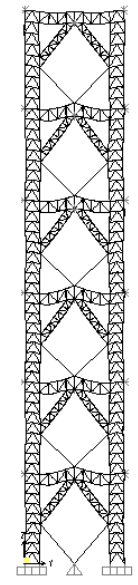

(a) Overall deformation

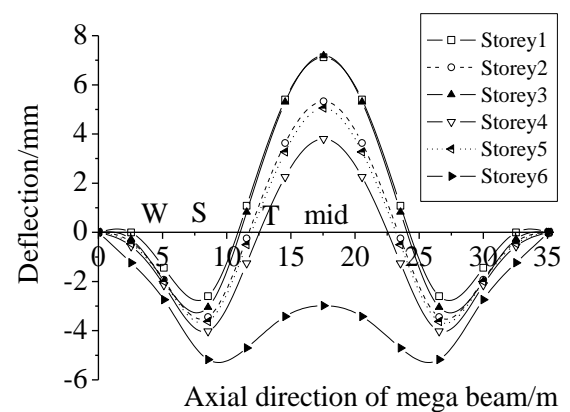

(b) Deflection of mega beam

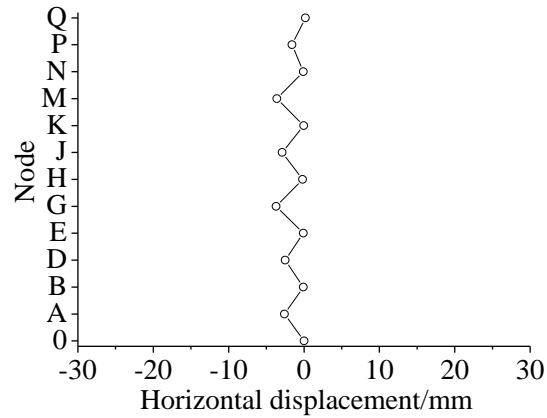

(c) Horizontal displacement of mega column

Fig. (7). Structural deformation under $P+V$

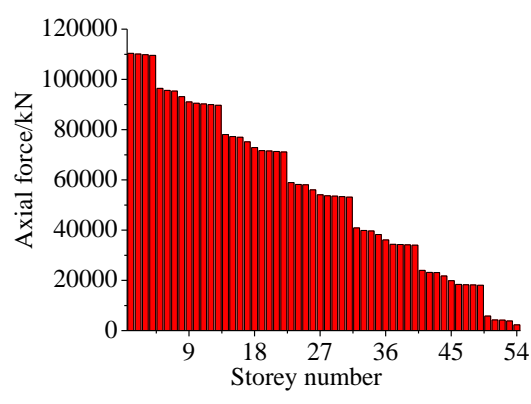

(a) Axial force

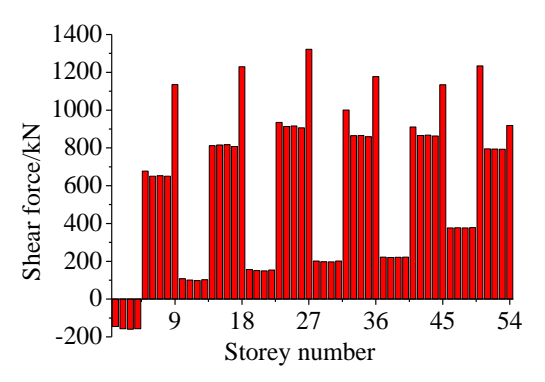

(b) Shear force

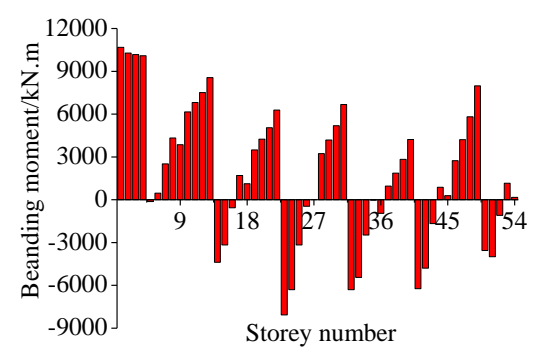

(c) Bending moment

Fig. (8). Internal forces in right-side mega column under $P+V$.

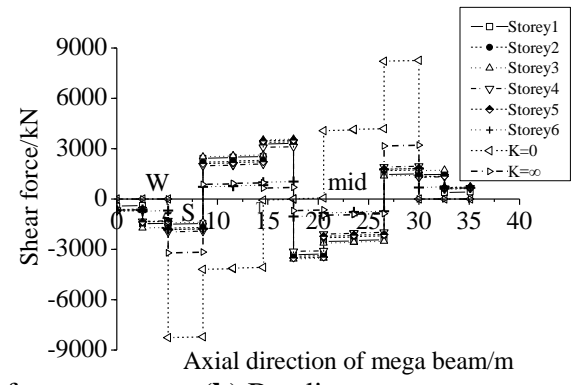

(b) Bending moment

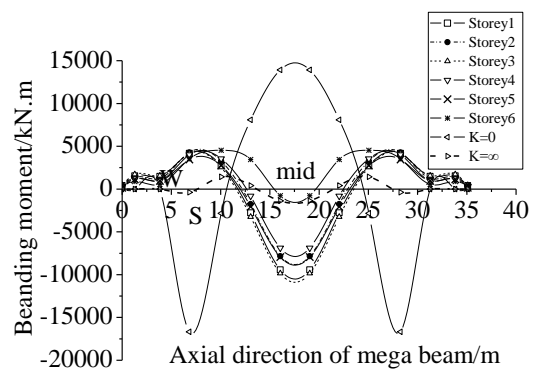

$\begin{array}{cc}\text { (a) Shear force } & \text { (b) Bending } \\ \text { Fig. (9). Internal forces in mega beams under } P+V \text {. }\end{array}$ 


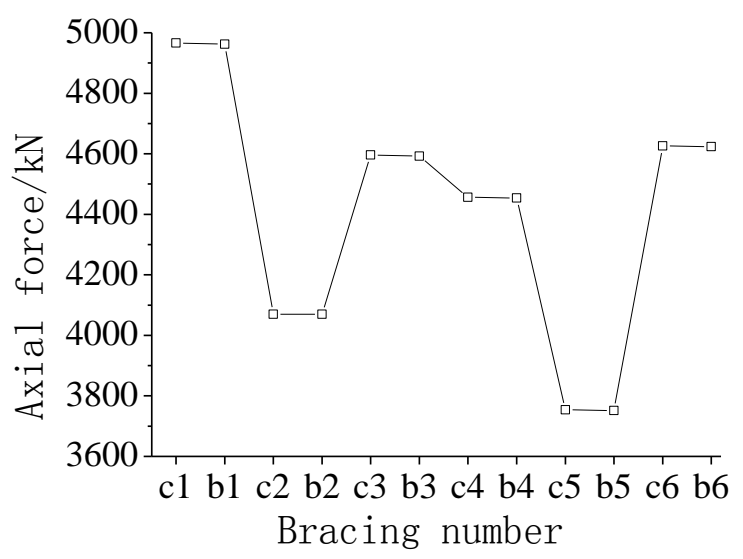

Fig. (10). Internal forces of composite bracings under $P+V$.

it can be seen that the shear force and bending moment are mainly generated by $P$. The bending moment is positive at each end and is negative at the middle part, which is accordance with the deformation diagram in Fig. (7b).

\subsubsection{Internal Forces of Composite Bracings}

Under the $P+V$ loads, the internal forces of composite bracings at each mega storey are in equilibrium and fluctuated around $4400 \mathrm{kN}$, and the maximum amplitude of difference between the maximum and minimum is $11 \%$ for all composite bracings. Since the $P+V$ condition is a high frequency case under the normal service condition, the equilibrium of internal forces under $P+V$ loads is very important. Comparison between Fig. (10) and Fig. (6) shows that the force increment of the rigid brace from $P$ to $P+V$ is greater than that of the cable, so the internal forces equilibrium of composite bracing can be achieved.

\subsection{Under Prestress, Vertical Loads and Horizontal Loads $(P+V+H)$}

\subsubsection{Structural Deformation}

As shown in Fig. (11), the horizontal deformation at the top under $P+V+H$ condition is $164.3 \mathrm{~mm}$ and the maximum storey drift appearing at Storey 42 is $4.5 \mathrm{~mm}$, which is about $1 / 900$ of storey height.

It can be concluded from the displacement curve of main structure in Fig. (11a) that the lateral stiffness is relatively

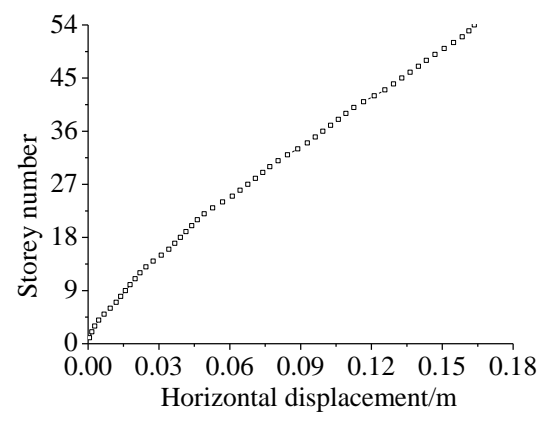

(a) Lateral displacement curve

Fig. (11). Lateral displacement and storey drift ratio under $P+V+H$.

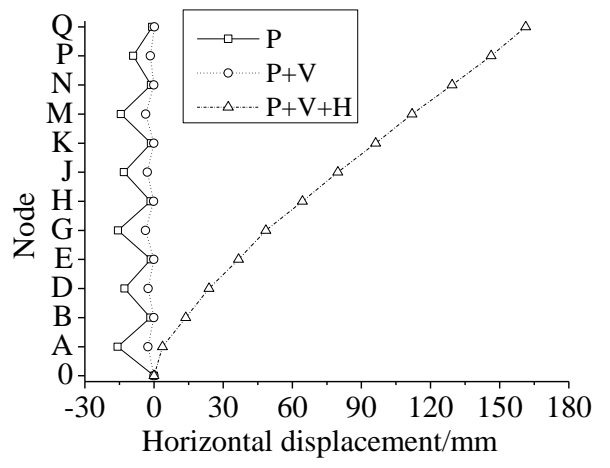

Fig. (12). Comparison of lateral displacement of mega column.

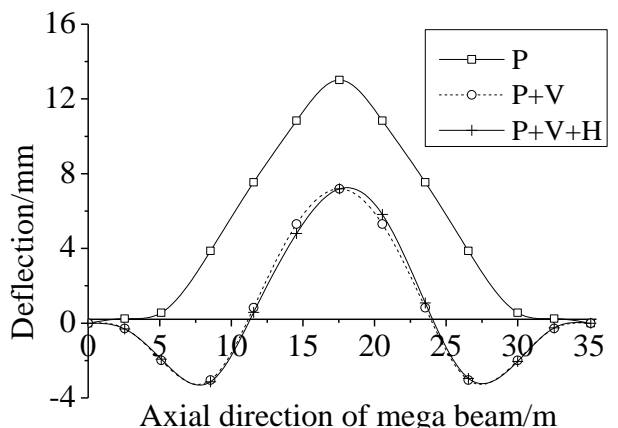

Fig. (13). Comparison of vertical displacement of mega beam.

uniform, which is governed by the structural form and the stiffness ratio of internal members. The displacement characteristic is flexure on the whole, while the bendingshearing deformation characteristic is significant at joint zones.

It can be found from Fig. (11b) that in each mega storey the maximum storey drift ratio appears at the storey where the rigid brace and the cable intersect, and then decreases both from upper direction and from lower direction. At the middle part of structure, the story drift ratio distribution is very uniform. At the bottom part, the storey drift varies dramatic in the cable segment, while keeps gentle in the rigid brace segment. At the top part, the variation pattern is opposite to that at the bottom part.

Further comparison of structural deformation is made among three load conditions. From Fig. (12), the horizontal displacement is mainly generated by horizontal load and the effect of prestress and vertical load can be ignored.

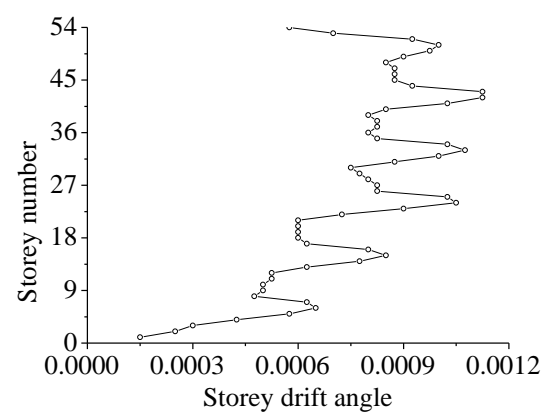

(b) Storey drift curve 


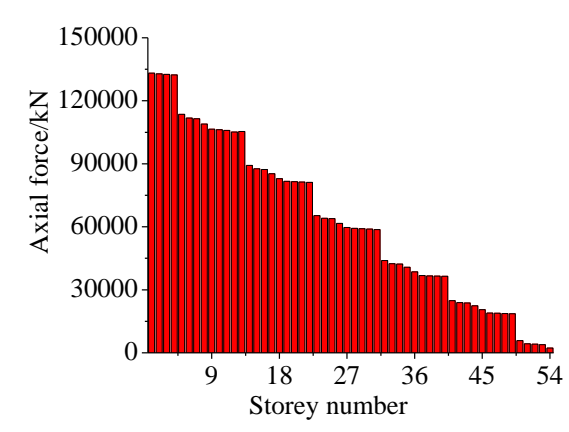

(a) Axial force

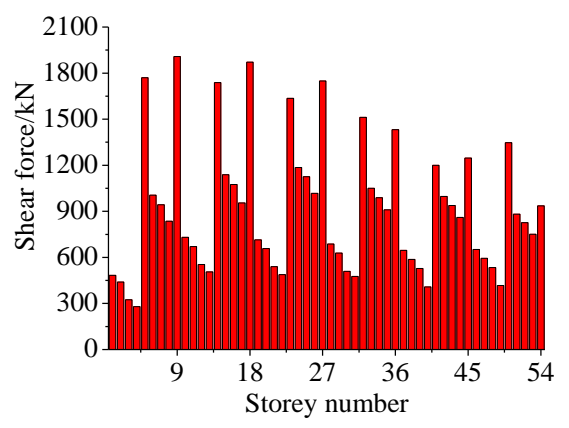

(b) Shear force

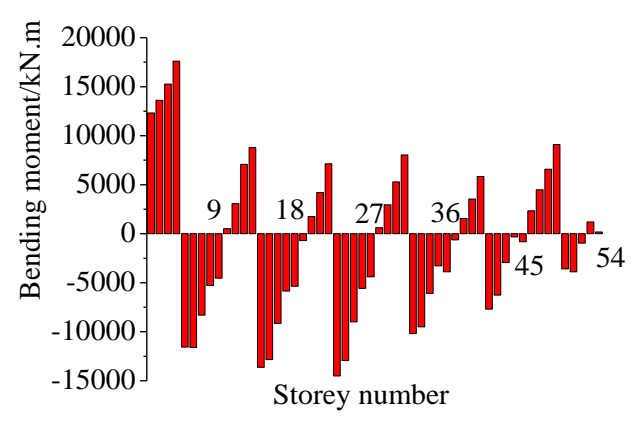

(c) Bending moment

Fig. (14). Internal forces of right-side mega column under $P+V+H$.

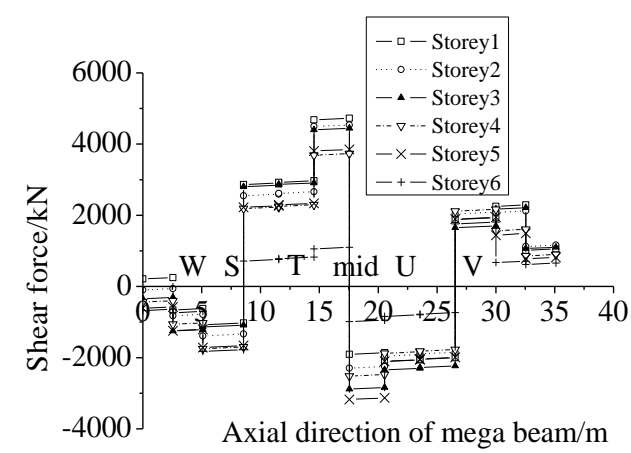

(a) Shear force

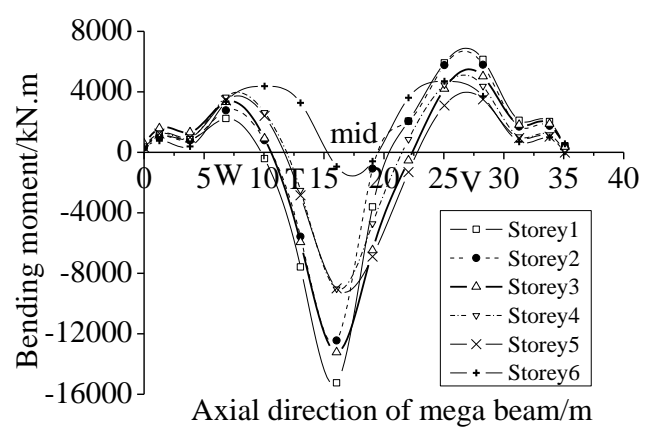

(b) Bending moment

Fig. (15). Internal forces in mega beam under $P+V+H$.

According to Fig. (13), the vertical displacement of mega beam is mainly generated by prestress and vertical load and the effect of horizontal load can be ignored.

\subsubsection{Internal Forces of Mega Column}

The right-side mega column is selected for analysis. The axial force distribution under $P+V+H$ condition is similar to that under $P+V$ condition, but the maximum axial force increases about $20 \%$. The shear force jump appears at the intersections of mega members and the rest stories gradually change due to uniform horizontal load. The maximum positive shear force is $1907 \mathrm{kN}$ and appears at the 9th storey. The bending moment of mega column turns direction at the intersection of composite bracing and mega column, and it is positive in the cable segment while is negative in the rigid

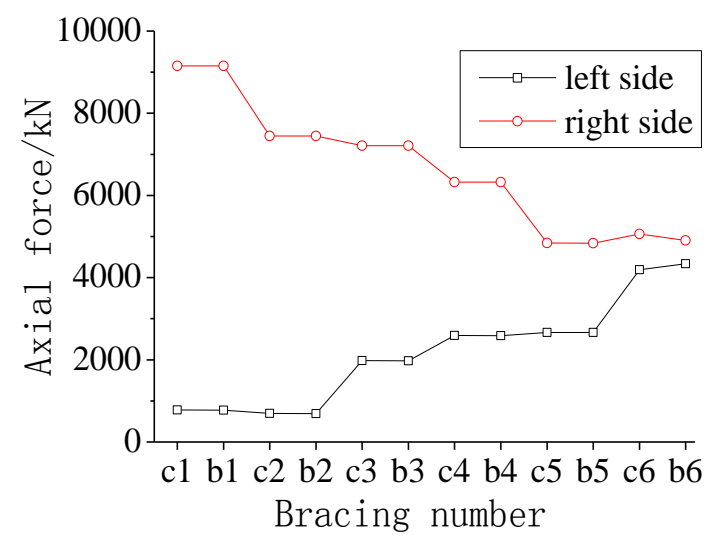

Fig. (16). Internal forces of composite bracings under $P+V+H$ brace segment. The maximum bending moment appearing at Storey 4 is $17605 \mathrm{kN} . \mathrm{m}$. On the whole, the internal forces of mega column are uniform along the height.

\subsubsection{Internal Forces of Mega Beam}

Under $P+V+H$ condition, the axial force diagram of mega column in Fig. (14) shows the stepped shape. Compared with Fig. (9), the internal forces distribution of mega beam under $P+V+H$ condition shown in Fig. (15) is similar to that under $P+V$ condition, but both the maximum shear force and bending moment increase. Taking Storey 1 as example, the maximum positive shear force increases about $42 \%$ from $3318 \mathrm{kN}$ to $4728 \mathrm{kN}$. The maximum positive bending moment appearing at the $1 / 4$ span increases about $50 \%$ from $4180 \mathrm{kN}$ to $6148 \mathrm{kN}$. The maximum negative bending moment appearing at the midpoint increases about $60 \%$ from $9424 \mathrm{kN} . \mathrm{m}$ to $15240 \mathrm{kN}$.m. The above variation phenomenon of mega beam internal force is decided by the existence of composite brace because the inner forces of bilateral braces are no longer equal to each other under horizontal load, so it is different from that in pure mega frame.

\subsubsection{Internal Forces of Composite Bracing}

As shown in Fig. (16), under $P+V+H$ loads, the axial force diagram of composite bracings shows the stepped shape and the composite bracings at each mega storey are in equilibrium except for Storey 6, where a slight difference is exists. The axial force of left bracings at bottom storey is close to zero, which is one general rule so as to save prestress for vertical prestressed structures where the prestressed cables together with other members resist 

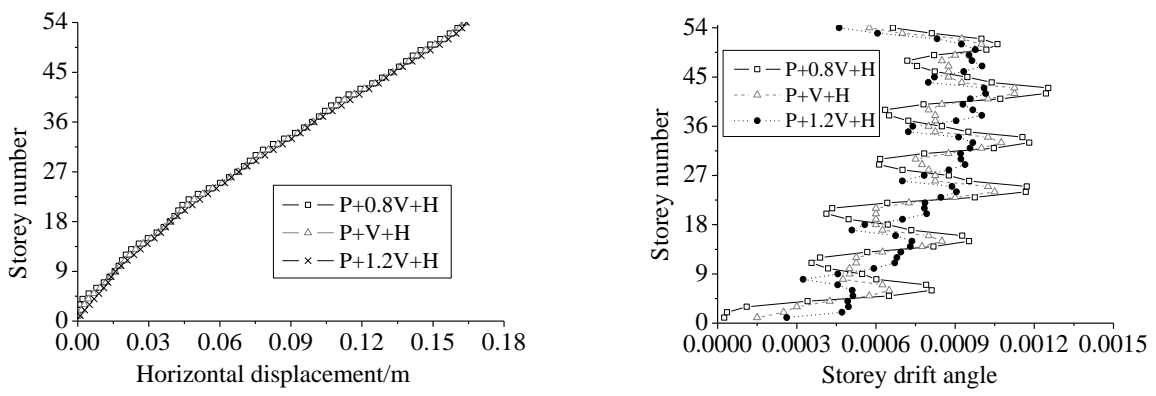

Fig. (17). Comparison of lateral displacement and storey drift ratio considering $\pm 20 \% \mathrm{~V}$.
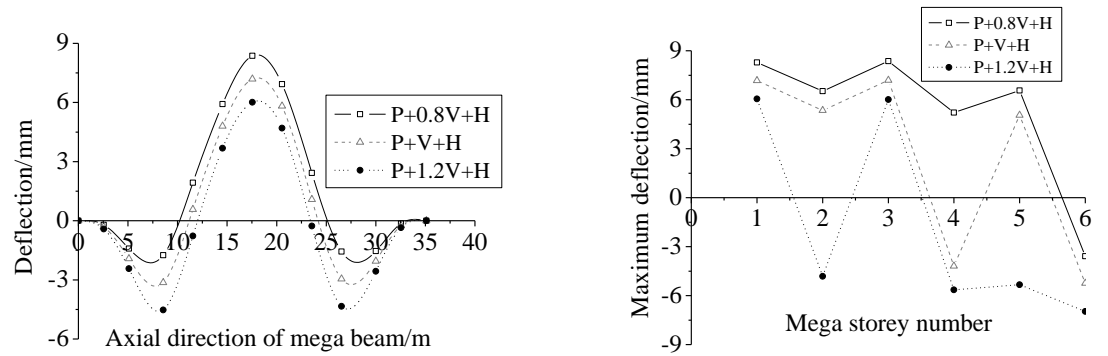

(a) Comparison of mega beam deflection in 3rd storey (b) Comparison of maximum mega beam deflection

Fig. (18). Comparison of mega beam deflection considering $\pm 20 \% \mathrm{~V}$.

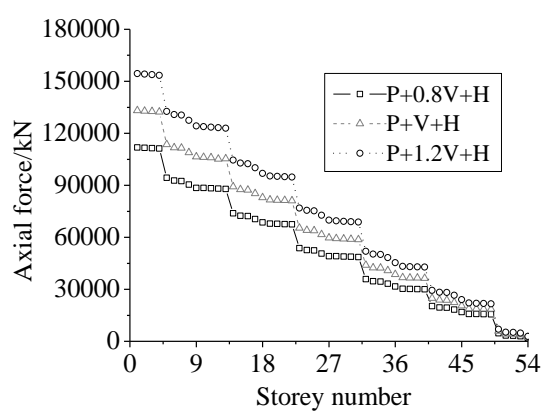

(a) Axial force

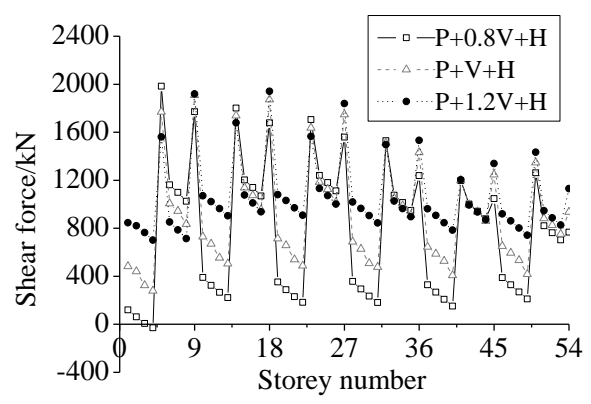

(b) Shear force

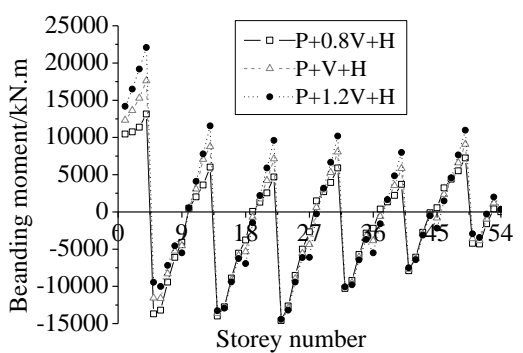

(c) Bending moment

Fig. (19). Comparison of internal forces in right-side mega column considering $\pm 20 \% \mathrm{~V}$.

horizontal load. At the same time, it can be found that the axial force of right bracing at bottom storey is nearly one time more than the average.

\subsection{Sensitivity Analysis of Load}

\subsubsection{Vertical Loads Variation}

The vertical loads of $D+0.5 \mathrm{~L}$ in this example that plus and minus $20 \%$ of fluctuation are nearly corresponding with " $D+L$ " condition and " $D$ " condition, which means $0.5 L$ accounts for about $20 \%$ of the sum of static vertical loads.

\subsubsection{Structural Deformation}

Fig. (17) shows that the variation of vertical loads within $20 \%$ range has almost no effect on the lateral displacement of the structure and storey drift distribution does not alter, however the storey drift value fluctuates slightly.

It can be seen from Fig. (18a) that the variation of vertical loads has a great influence on mega beam deflection. When vertical load decreasing, the upward convex at middle part is more significant, while the deflection at the $1 / 4$ span decreases evidently, and vice versa. So it is confirmed that the location of maximum deflection will change with vertical load variation. The maximum deflection at each mega beam is less than $9 \mathrm{~mm}$ that is about 1/3300 mega beam span under three conditions.

\subsubsection{Internal Forces of Mega Column}

As shown in Fig. (19), internal forces at mega column fluctuate with the variation of vertical loads, but their distribution characteristics remain unchanged. The variation of vertical loads has an obvious effect on the axial force, especially for those columns near the bottom. The shear force in the cable segment changes significantly, but changes a little in the rigid brace segment. The bending moments of mega columns at the bottom change greatly, but change a little at other places.

\subsubsection{Internal Force of Mega Beam}

It can be found from Fig. (20) that the internal forces of mega beams fluctuate with the variation of vertical loads, but their distribution characteristics remain unchanged. Taking mega beam at storey 1 as example, the shear force under $P+1.2 \mathrm{~V}+\mathrm{H}$ condition is greater than those under $\mathrm{P}+\mathrm{V}+\mathrm{H}$ condition. The shear forces at both ends increase obviously, while increases about $3 \%$ on the middle part. Under the 


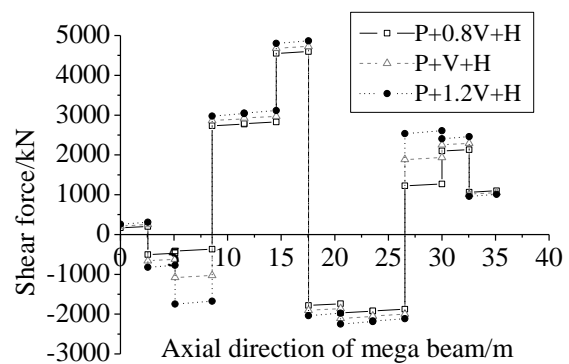

(a) Shear force at storey 1

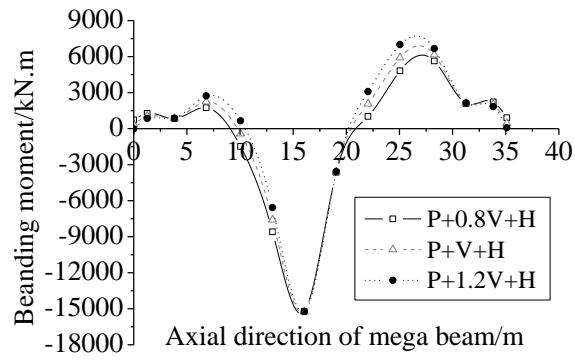

(d) Bending moment at storey 1

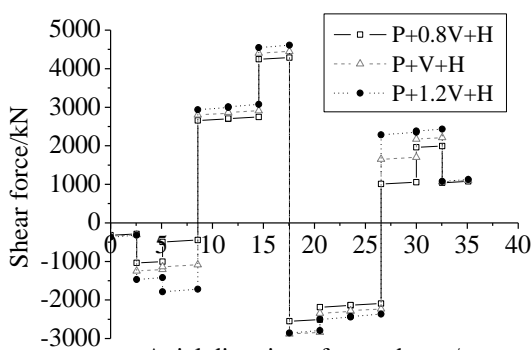

Axial direction of mega beam $/ \mathrm{m}$

(b) Shear force at storey 3

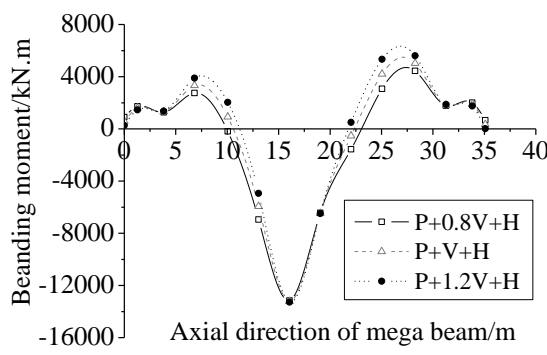

(e) Bending moment at storey 3

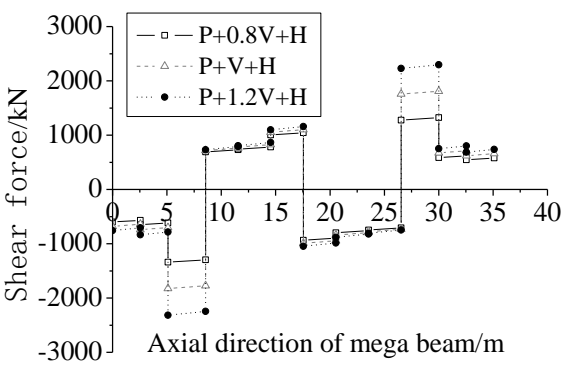

(c) Shear force at storey 6

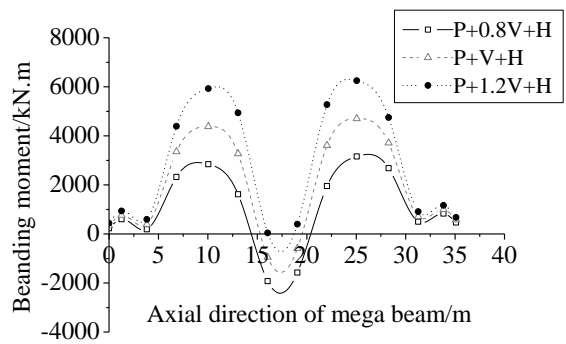

(f) Bending moment at storey 6

Fig. (20). Comparison of inter forces in mega beam considering $\pm 20 \% \mathrm{~V}$.

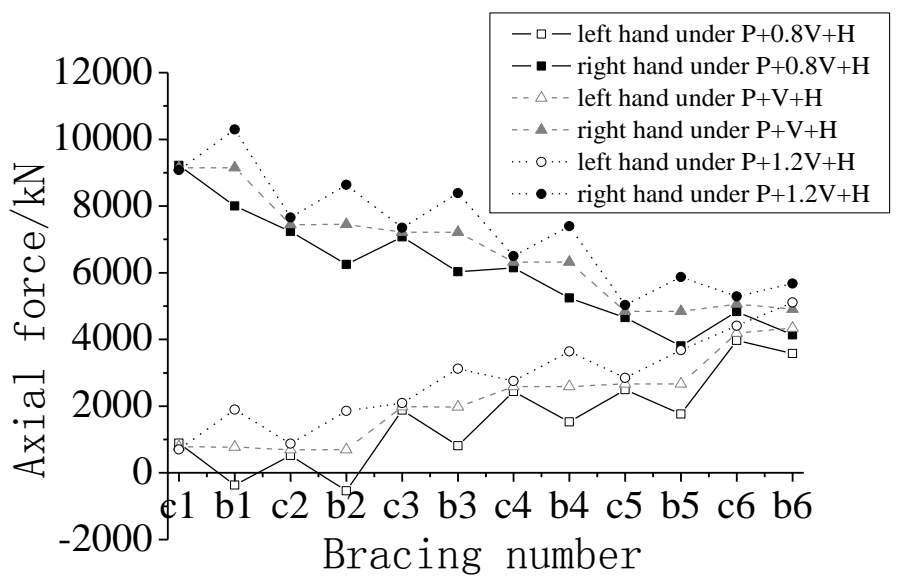

Fig. (21). Comparison of internal forces in composite bracing considering $\pm 20 \% \mathrm{~V}$.

$P+0.8 V+H$, it is on the contrary. Under $P+1.2 V+H$ condition, the maximum positive bending moment appearing at the $3 / 4$ span is $6662, \mathrm{kNm}$, which increases by about $8 \%$ compared with that under $P+V+H$ condition. Need to pay attention to the top mega beam, where bending moment increases by about $50 \%$ because one part of vertical loads on the lower mega beam are transferred to the top mega beam through the composite bracing.

\subsubsection{Internal Force of Composite Bracing}

It can be seen from Fig. (21) that the variation of vertical loads leads to the disequilibrium of internal forces at composite bracings and the internal force increment at rigid bracing is greater than that at cable, so the vertical load plays a decisive role for internal forces equilibrium of composite bracings. Taking the composite bracings at the bottom storey as an example, the degree of disequilibrium is about $13 \%$ under the $P+1.2 \mathrm{~V}+H$ loads and about $15 \%$ under the $P+0.8 V+H$ loads.

\subsubsection{Horizontal Load Variation}

\subsubsection{Structural Deformation}

It is shown in Fig. (22) that horizontal load variation only has influence on the value of horizontal displacement and storey drift ratio, and does not change their distribution pattern. The top horizontal displacement under $\mathrm{P}+\mathrm{V}+0.8 \mathrm{H}$ condition is about $130.7 \mathrm{~mm}$ and deceases about $20.1 \%$ compared with that under $P+V+H$ condition, while the value under $P+V+1.2 H$ condition is about $197 \mathrm{~mm}$ and increases about $20.1 \%$. So on the whole the lateral displacement and storey drift are proportional to horizontal load due to the elastic structure.

As shown in Fig. (23), the effect of horizontal load variation within $20 \%$ range on mega-beam deflection can be ignored. 

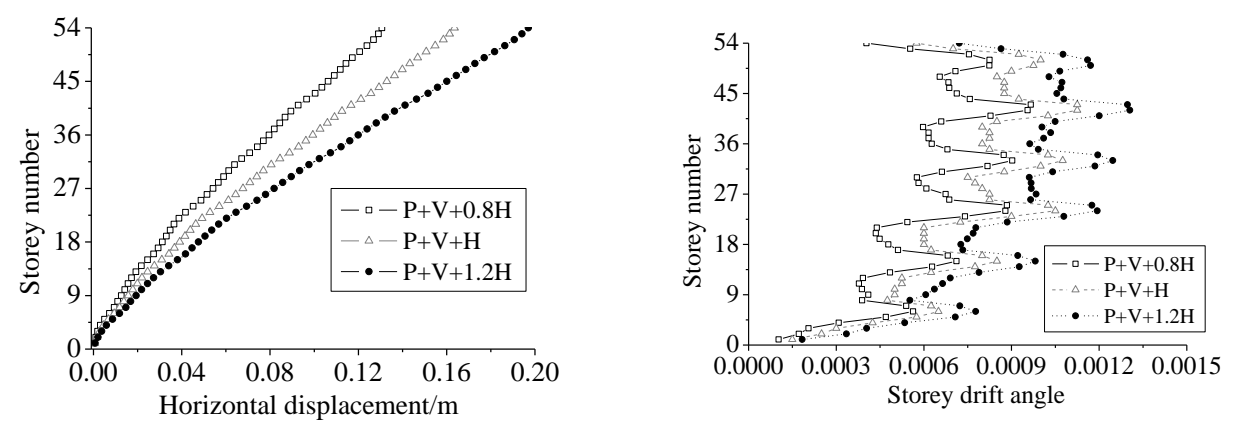

Fig. (22). Comparison of lateral displacement and storey drift ratio considering $\pm 20 \% \mathrm{H}$.

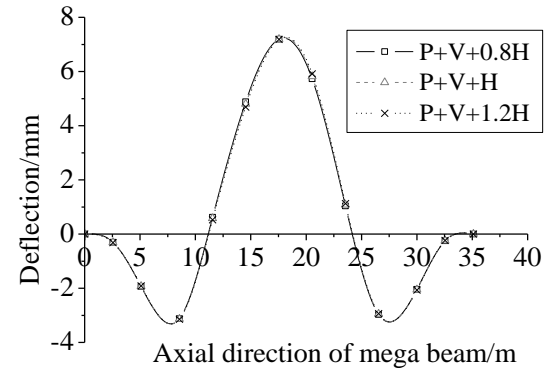

(a) Comparison of mega beam deflection in 3rd storey

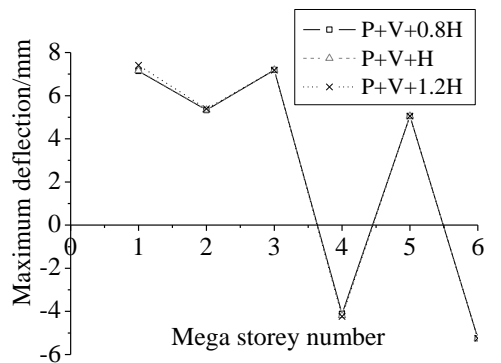

(b) Comparison of maximum mega beam deflection

Fig. (23). Comparison of mega beam deflection considering $\pm 20 \% \mathrm{H}$.

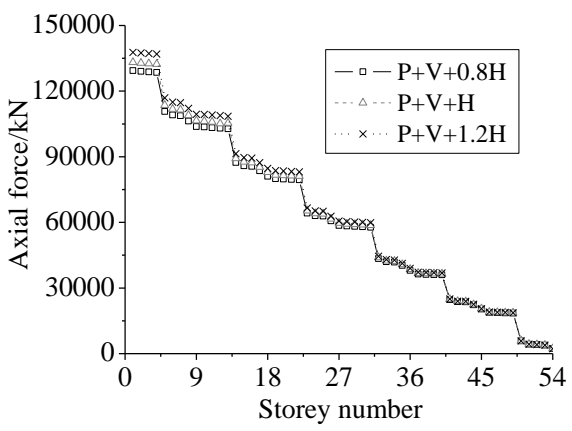

(a) Axial force

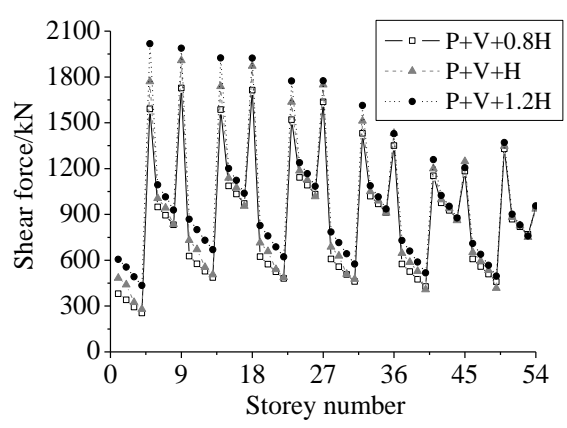

(b) Shear force

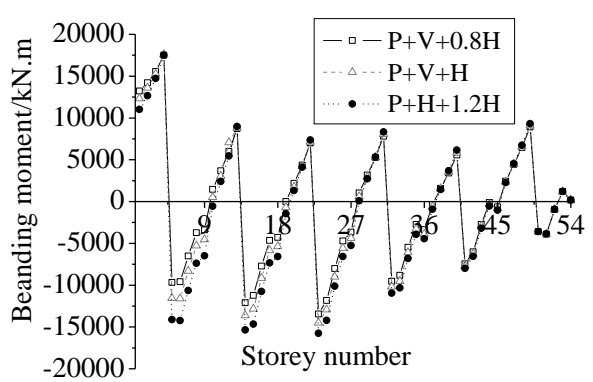

(c) Bending moment

Fig. (24). Comparison of internal forces in right-side mega column considering $\pm 20 \% \mathrm{H}$.

\subsubsection{Internal Forces of Mega Column}

As shown in Fig. (24), the distribution pattern of internal forces at mega-column doesn't change, however the values of internal forces especially at the structural bottom change obviously due to cumulative effect of horizontal load. The shear force variation of mega columns in the cable segment is greater than that in the rigid brace segment and there is a positive relationship between the shear force of mega column and horizontal load.

\subsubsection{Internal Force of Mega Beam}

Comparison of the shear force and bending moment of the mega beams at storey 1, 3 and 6 as shown in Fig. (25) under different horizontal loads is made. It is obvious that the internal forces of mega beam change little.

\subsubsection{Internal Forces of Composite Bracings}

As shown in Fig. (26), the internal forces of composite bracings are in equilibrium no matter how the antisymmetric horizontal load varies. Under $P+V+1.2 H$ condition, the upwind cables at the two bottom stories quit work and the rigid brace at storey 1 is slightly tensioned.

\subsection{Comparison with Mega Frame and Mega Truss}

The numerical model of steel mega frame structure (MFS) can be simply built by deleting all the composite bracings in the steel mega frame and pre-stressed composite brace structure (MFPCBS). The numerical model of steel mega truss structure (MTS) can be built by substituting all the composite bracings of the steel MFPCBS with diagonal truss braces, which has the same section as the rigid $\Lambda$-shape brace in MFPCBS. Comparison of the three different structures is made under the final load condition (for the MFS and MTS is $V+H$, and for the MFPCBS $P+V+H$ ).

\subsubsection{Structural Deformation}

As shown in Fig. (27), the maximum mega beam deflection in MFPCBS is about $7.2 \mathrm{~mm}$ under the final load condition, which is about $1 / 5$ of that in MTS or MFS. 


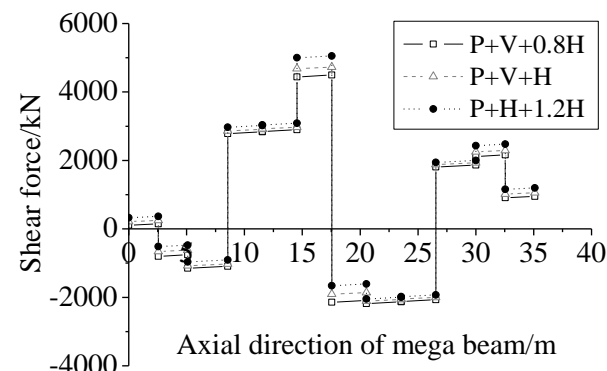

(a) Shear force at storey 1

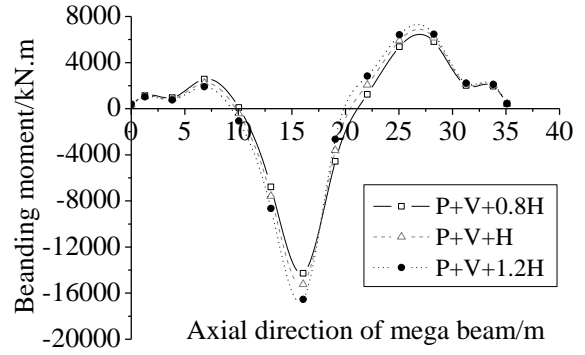

(d) Bending moment at storey 1

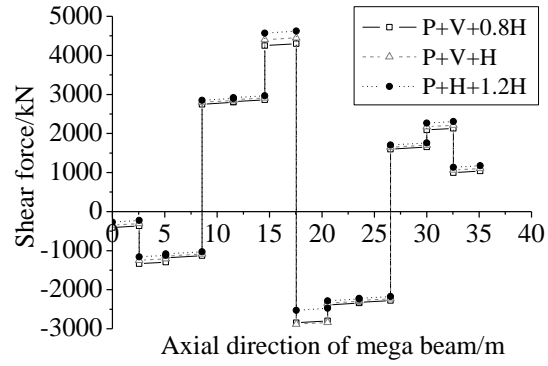

(b) Shear force at storey 3

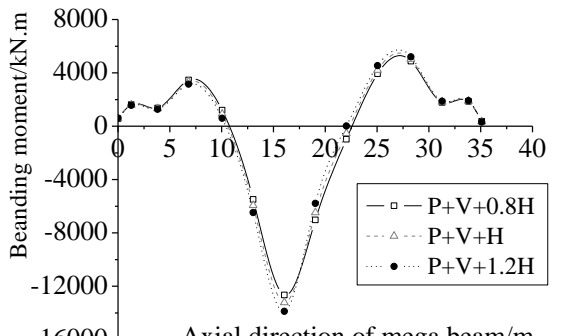

(e) Bending moment at storey 3

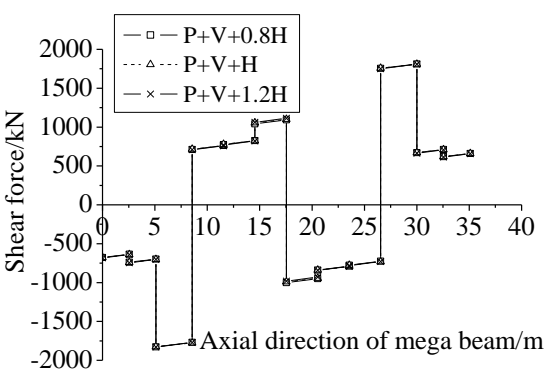

(c) Shear force at storey 6

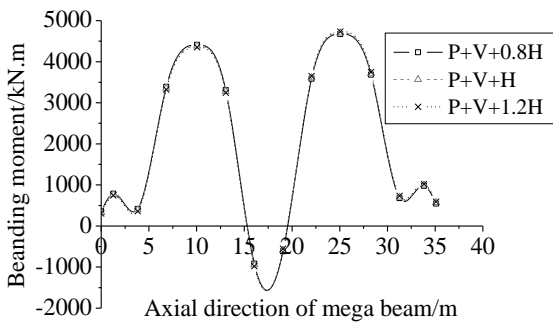

(f) Bending moment at storey 6

Fig. (25). Comparison of internal forces of mega beam considering $\pm 20 \% \mathrm{H}$.

Because the composite bracing transfers part of the loads at the mega beam to the near mega column, the deflection of the mega beam is dramatically reduced and then the performance of the mega-beam is improved.

It can be seen from Fig. (28) that the top horizontal displacement of MFPCBS is much smaller than that of MFS and close to that of MTS, which means that the composite bracing can not only bear vertical load together with mega beam, but also greatly improve the lateral stiffness of the frame structure. It is important that the maximum storey drift ratio in MFPCBS is significantly less than that in the other two systems and the fluctuation amplitude of storey drift ratio diagram in MFPCBS is relatively much small, which means that the lateral stiffness distribution of MFPCBS is more homogeneous.

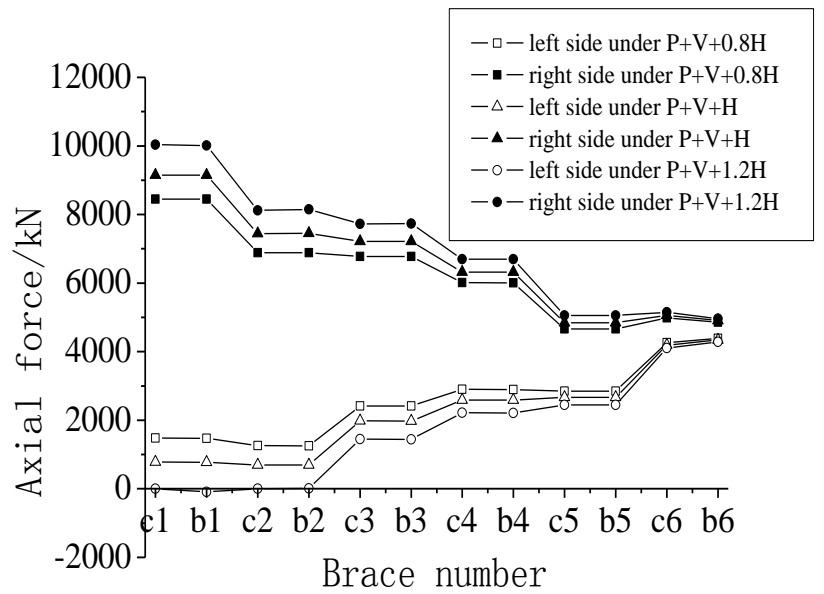

Fig. (26). Comparison of internal forces in composite bracings considering $+20 \% \mathrm{H}$.

\subsubsection{Internal Forces of Mega Column}

Under the final load condition, the maximum axial force at mega column of MFPCBS is greatest among three systems as shown in Fig. (29a), which can be explained by that the composite bracing transfers the load on the mega beam to the mega column and the effect of prestress of cables.

As shown in Fig. (29b), the maximum shear force of mega column of $1907 \mathrm{kN}$ in MFPCBS is reduced by about $78 \%$ and $43 \%$ respectively, compared with that of $9001 \mathrm{kN}$ in MFS and of $3359 \mathrm{kN}$ in MTS. So MFPCBS is a highly efficient system from the view of bearing shear force.

Fig. (29c) further shows that the maximum bending moment of mega column of $17605 \mathrm{kN}$.m in MFPCBS is reduced by about $85 \%$ and $22 \%$ respectively, compared with that of 121145 kN.m in MFS and of 22491 kN.m in MTS. So in the view of bearing bending moment, MFPCBS is a highly efficient system.

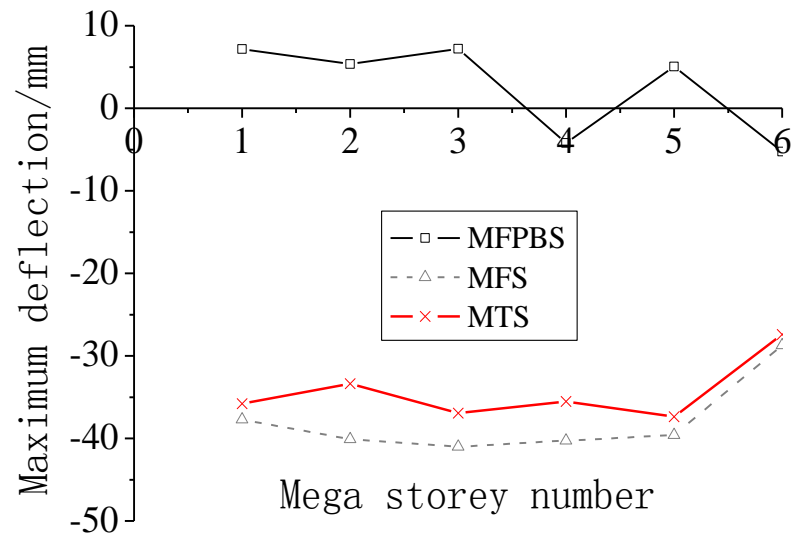

Fig. (27). Comparison of maximum deflection of mega beam among three systems. 

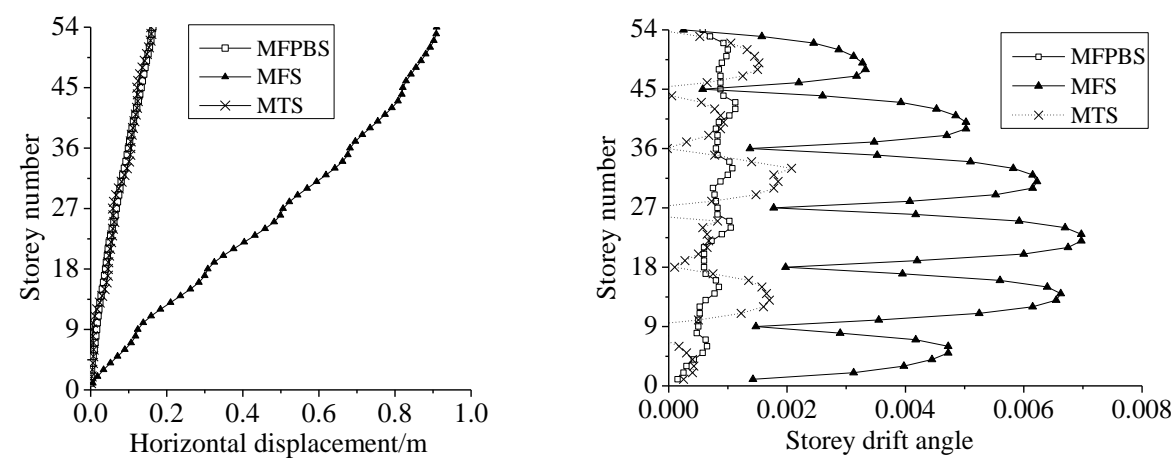

Fig. (28). Comparison of lateral displacement and storey drift ratio among three systems.

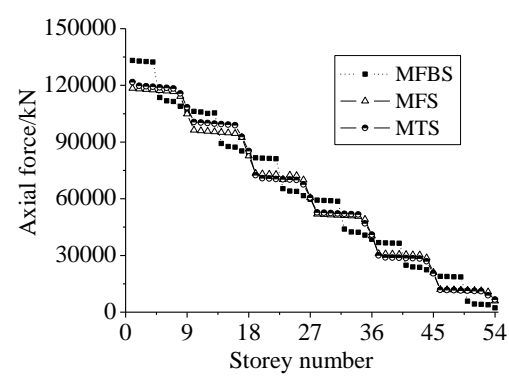

(a) Axial force

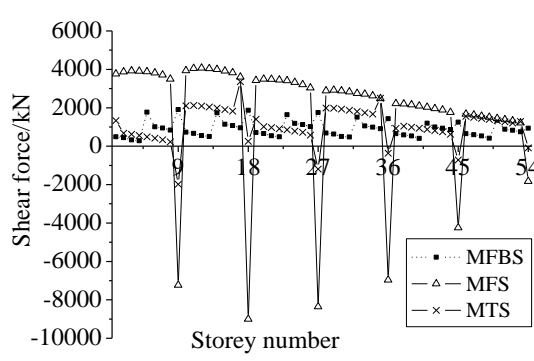

(b) Shear force

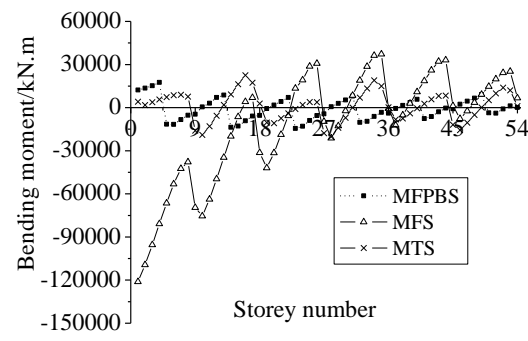

(c) Bending moment

Fig. (29). Comparison of internal forces in right-side mega column among three systems.

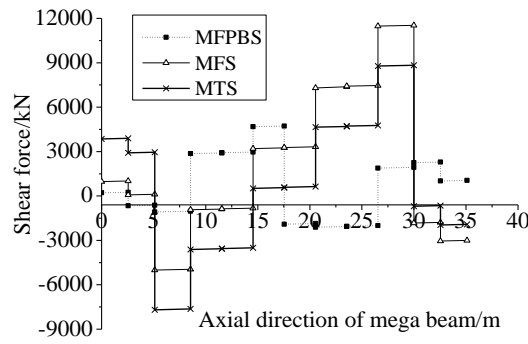

(a) Shear force at storey 1

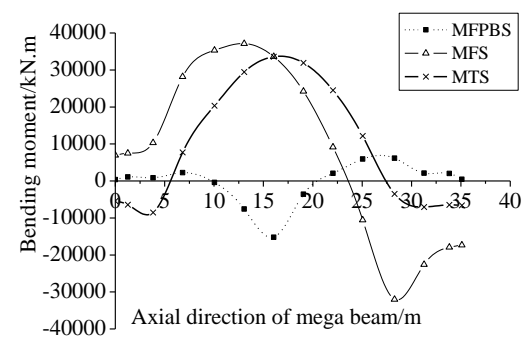

(d) Bending moment at storey 1

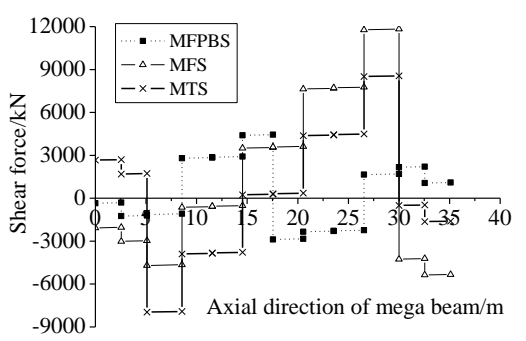

(b) Shear force at storey 3

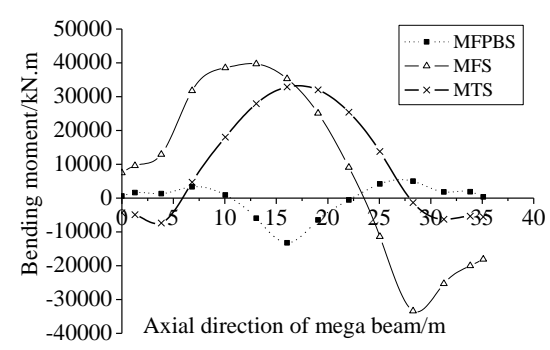

(e) Bending moment at storey 3

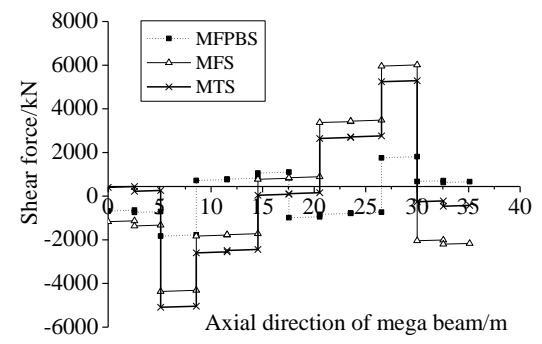

(c) Shear force at storey 6

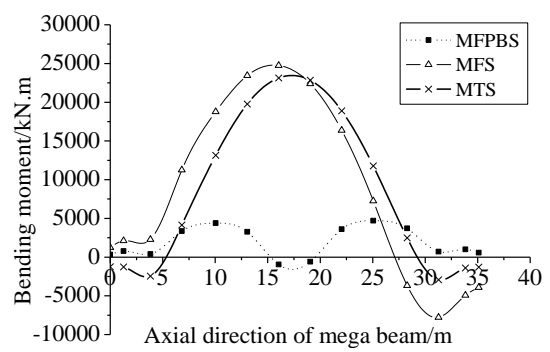

(f) Bending moment at storey 6

Fig. (30). Comparison of internal forces in mega beam among three systems.

\subsubsection{Internal Forces of Mega Beam}

Comparison of internal forces of mega beam at storey 1 , storey 3 and storey 6 among three systems is shown in Fig. (30).

Compared with the other two systems, the maximum shear forces and bending moment of mega beam in MFPCBS is reduced significantly, which demonstrates that mega beam's performance in MFPCBS is improved. Taking mega beam in storey 1 as example, the maximum shear force of $4682 \mathrm{kN}$ in MFPCBS is reduced by about $60 \%$ and $47 \%$ respectively, compared with that of $11528 \mathrm{kN}$ in MFS and of
$8836 \mathrm{kN}$ in MTS. The maximum bending moment in MFPBS is $15240 \mathrm{kN} . \mathrm{m}$, which is reduced by about $59 \%$ and $55 \%$ respectively, compared with 37148 kN.m in MFS and 33576 kN.m in MTS.

\section{SEISMIC PERFORMANCE ANALYSIS}

\subsection{Seismic Wave}

According to the relationship between acceleration spectrum and velocity spectrum is $S_{a}=\omega S_{v}$, the seismic influence coefficient curve in Chinese code for seismic design of buildings (GB50011-2010) can be transferred to velocity spectrum, which is taken as the target velocity 


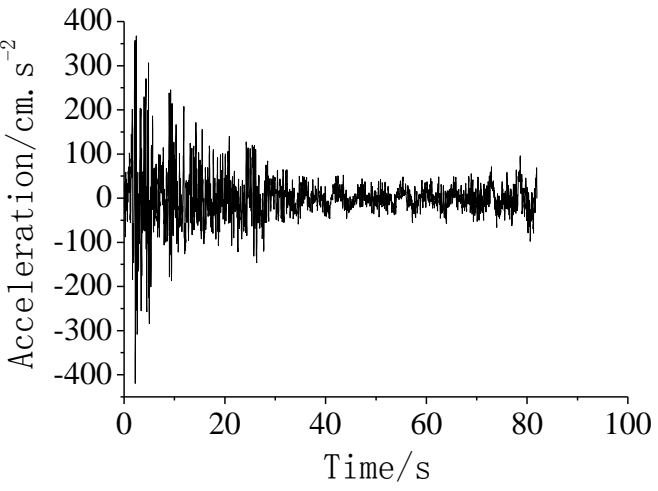

(a)ART EL CENTRO wave

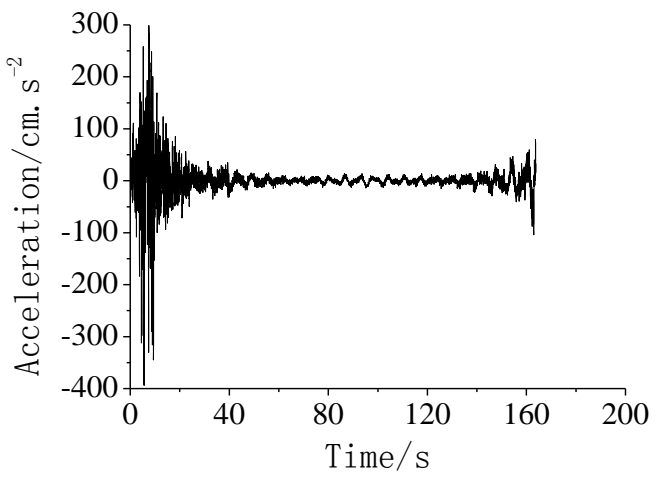

(c) ART KOBE wave

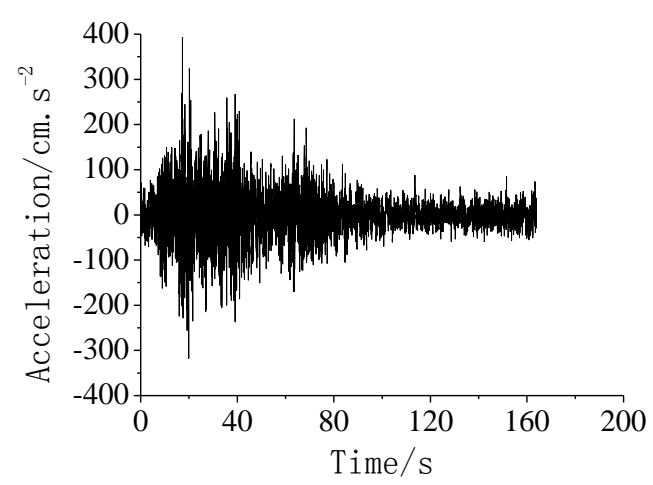

(b)ART HACHINOHE wave

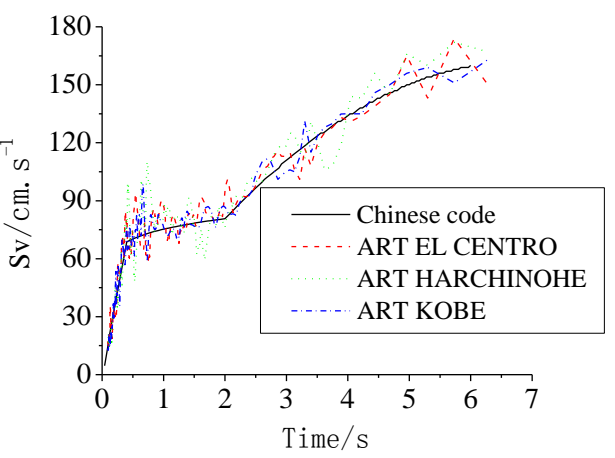

(d) Velocity spectrum fitting

Fig. (31). Earthquake waves.

Table 2. Parameters of rare artificial earthquake wave.

\begin{tabular}{|c|c|c|c|c|c|}
\hline Artificial Earthquake & Phase Characteristics & $\mathrm{Dt} / \mathrm{s}$ & Length/s & Maximum/Gal & Time/Sec \\
\hline ART EL CENTRO & EL CENTRO 1940 NS & 0.01 & 81.92 & 419.15 & 2.22 \\
\hline ART KOBE & JMA KOBE 1995 NS & 0.01 & 163.84 & 393.85 & 5.56 \\
\hline
\end{tabular}

spectrum in this example. Then the phase characteristics of seismic EL CENTRO 1940 NS, HACHINOHE 1968 EW and JMA KOBE $1995 \mathrm{NS}$ are used to form the frequent and rare

artificial earthquake waves. The seismic fortification basic intensity is 8 degree, the classification of design earthquake is group 1 and the site soil classification is class II. The velocity spectrum of artificial wave is fitted with the target spectrum. The parameters of the rare artificial earthquake wave are shown in Table 2. Fig. (31d) shows the design seismic velocity spectrum curve and the velocity spectrum curves of ART EL CENTRO, ART HACHINOHE and ART KOBE, respectively. A good agreement is found between the design velocity spectrum curve and the velocity spectrum curve of the artificial earthquake.

\subsection{Optimization of Damping}

When the relative displacement of main structure and substructure is large enough, collision is easily appeared between them. So the damper is installed to reduce the lateral displacement.
Under ART EL CENTRO earthquake wave, the relationship between additional damping and the top displacement of the structure is shown in Fig. (32). It can be found that the horizontal vibration displacement of the

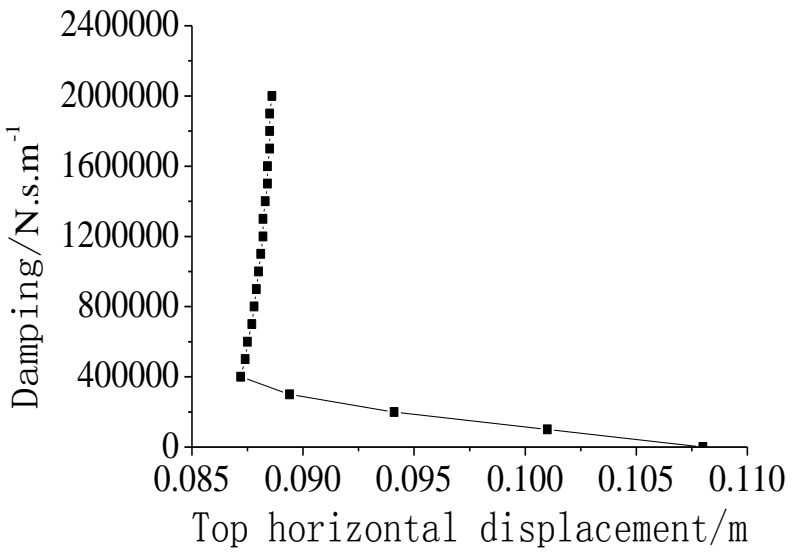

Fig. (32). Curve of additional damping and top displacement. 
structure is not boundlessly reduced with the increase of additional damping, which has an optimal value of about 400 $\mathrm{kN} . \mathrm{s} / \mathrm{m}$ for ART ELCENTRO earthquake wave.

\subsection{Analysis of Energy Dissipation}

\subsubsection{Energy Distribution of Overall Structure}

Fig. (33) is the time history curves of structure kinetic energy (potential energy), damping consumption energy and structure plastic deformation energy under three different earthquake waves. The damping consumes about $90 \%$ of input energy from earthquake, and the plastic deformation energy is very little, which means that most members are still in elastic stage and that the seismic performance of the MFPCBS is excellent.

\subsubsection{Energy Consumption of Main Structure and Substructure}

It is hoped that the substructure can consume most energy to protect main structure from being destroyed. Fig. (34) shows plastic deformation energy comparison between main and sub structures under three different earthquake waves. Obviously the plastic deformation energy only exits in substructure and main structure keeps elastic state, which meets expectation.

\section{PUSHOVER ANALYSIS}

Only the main structure was analyzed with the pushover analysis method in this paper, and the substructure is used as the gravity load representative values in the way of

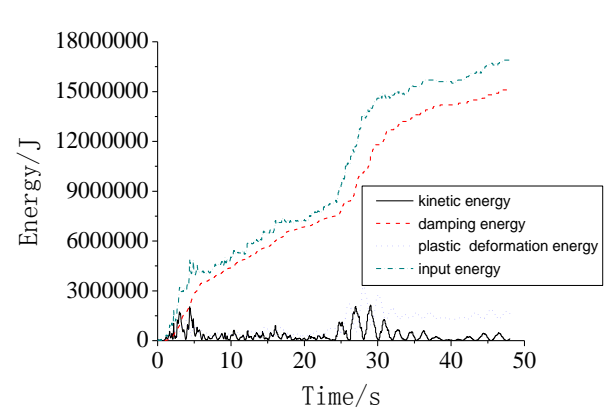

(a)ART ELCENTRO

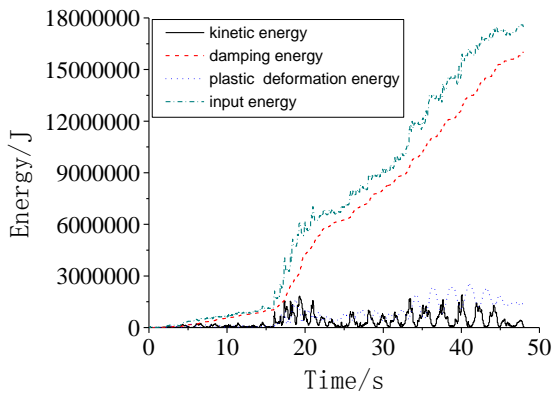

(b) ART HACHINOHE

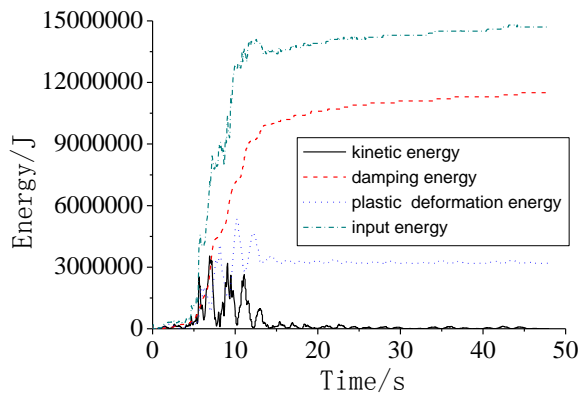

(c) ART KOBE

Fig. (33). Energy distribution of overall structure.

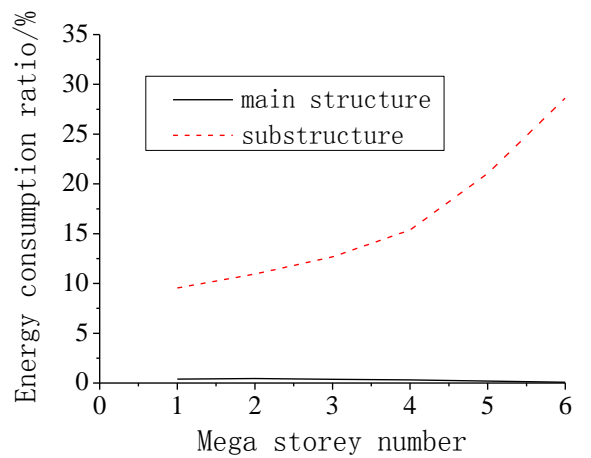

(a) ART EL CENTRO

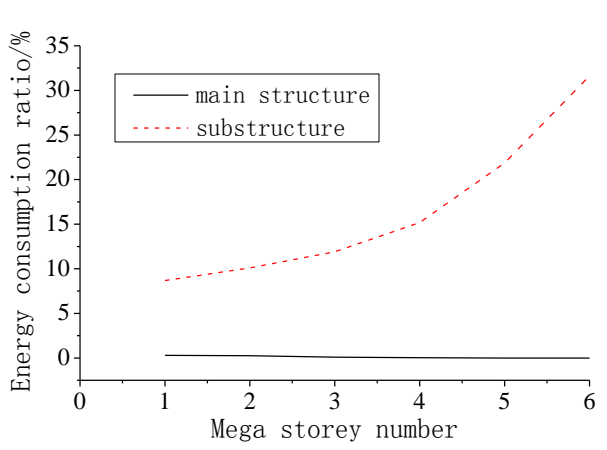

(b) ART HACHINOHE

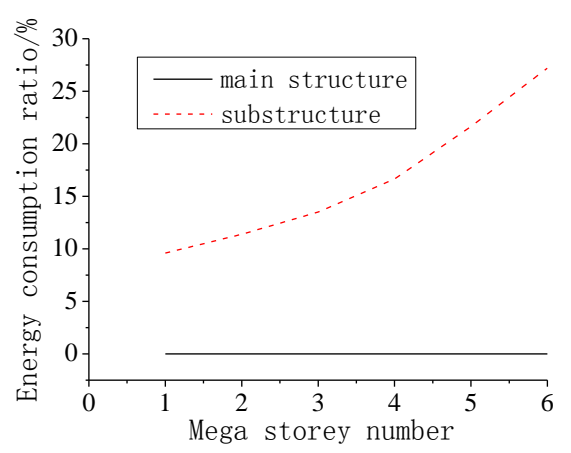

(c) ART KOBE

Fig. (34). Energy dissipation in main and sub structures.

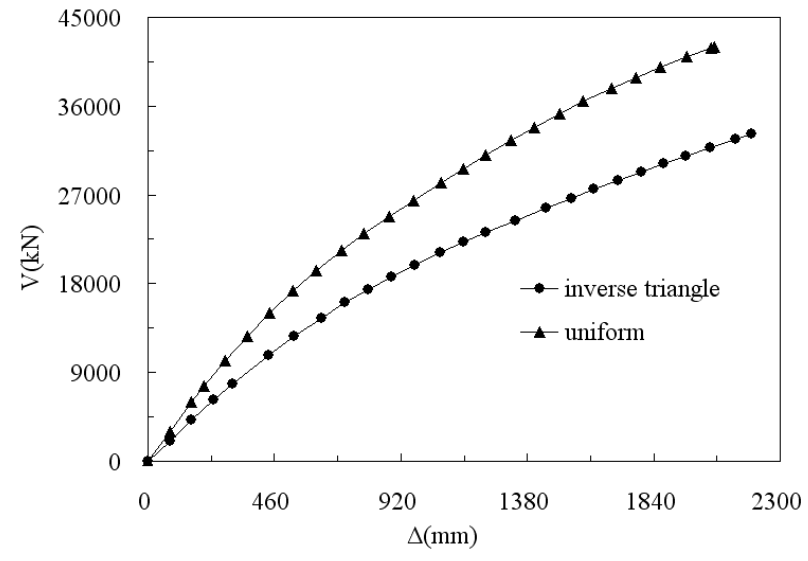

(a) Base shear-roof displacement

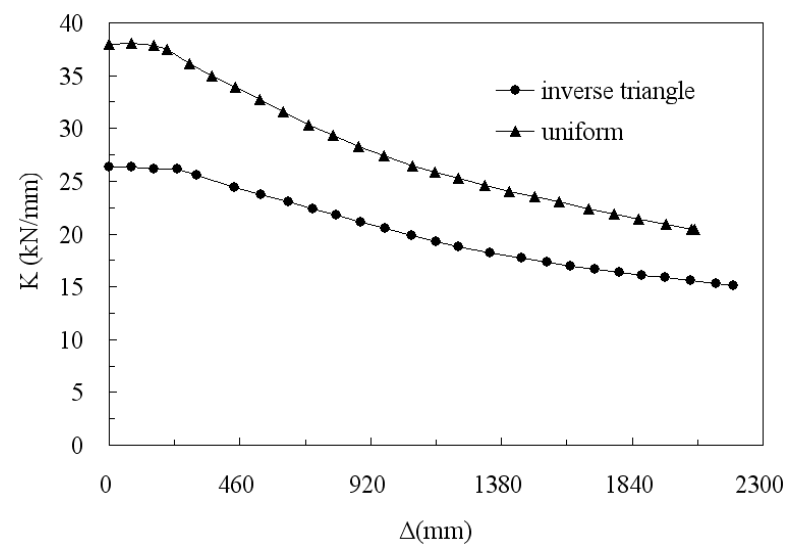

(b) Lateral stiffness-roof displacement

Fig. (35). Base shear and lateral stiffness 
concentrated force to apply on the mega beam.

The mega steel frame-prestressed composite bracing structure is carried out the pushover analysis by using the finite element analysis software SAP2000. The P-MM plastic hinge is set at the ends of giant column limb and the MM plastic hinge is set at the ends of floor beams, giant beam chords, plane truss chords and giant $\Lambda$-shape steel brace chord. The frame element only bearing axial load where the $\mathrm{P}$ hinge is set at the middle of members is used for the braces between giant column limbs, web members of giant beam, web members of plane truss and web members of giant $\Lambda$-shape steel brace truss. The frame element only bearing tension is used for the pre-stressed cable and the axial $P$ hinge is also set at the middle of member. The FEMA model is used for all the plastic hinges.

The vertical load and pre-tension are applied on structure at first so that the static nonlinear analysis will be conducted before carrying out Pushover analysis and the P- $\Delta$ effect is took into account. The two different lateral load distributions of uniform distribution and inverse triangle distribution are applied in the Pushover analysis for the mega steel frameprestressed composite bracing structure [16,17].

The recommended method in FEMA-273 [18] or ATC-40 [19] used in SAP2000 is adopted to evaluate the seismic performance of members.

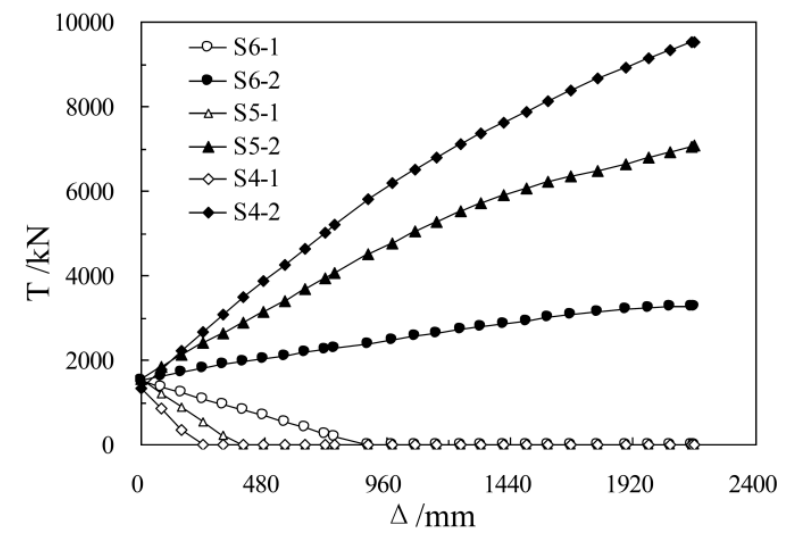

(a) Cables at upper three large layers

\subsection{Base Shear and Lateral Stiffness}

The curves of base shear and lateral stiffness varying with the roof displacement are shown in Fig. (35a and b), respectively. It can be seen from the graph that the different horizontal loading patterns have a major influence on the curves of structural performance.

Fig. (35a) shows that with the horizontal load increasing, the structural system gradually transits from elastic state to elasto-plastic state and the curve of base shear and roof displacement varies from a line segment to curve segment with the slope gradually decreasing. Finally, when the horizontal load increases to a maximum value, this structural system reaches the limit state of destruction because of forming a lot of plastic hinges in structure. The horizontal maximum load of system obtained from Pushover analysis for the lateral inverse triangular distribution is less than that for the uniform distribution. The former ultimate bearing capacity is $38714 \mathrm{kN}$ and the corresponding displacement is $2160 \mathrm{~mm}$. While, the latter is $43007 \mathrm{kN}$ and roof displacement is $1585 \mathrm{~mm}$. It is also known from the graph that the roof displacement under the inverse triangular distribution is larger than that under the uniform distribution when bearing the same horizontal load.

It can be seen from Fig. (35b) that when the horizontal load gradually increases, the resisting lateral stiffness of

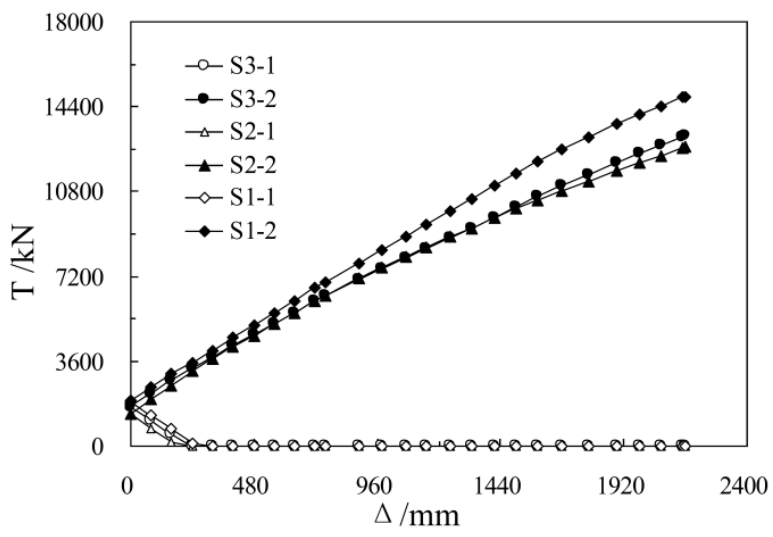

(b) Cables at lower three large layers

Fig. (36). The tension of cables and roof displacement under the horizontal load of inverse triangle distribution.

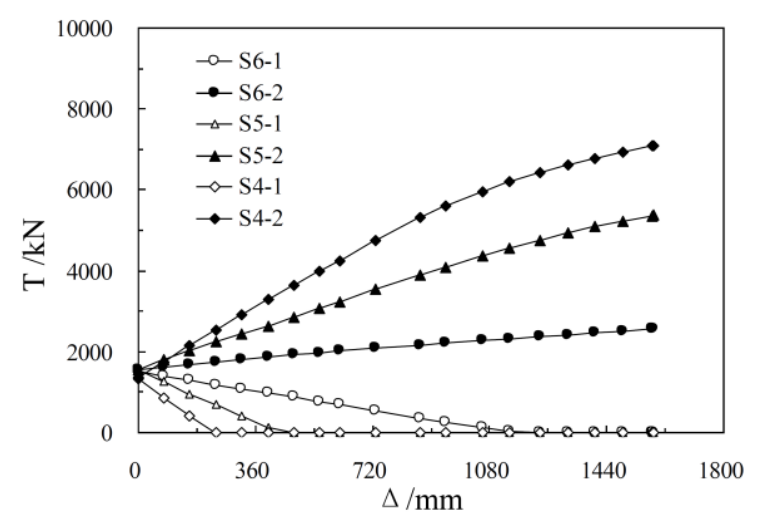

(a) Cables at upper three large layers

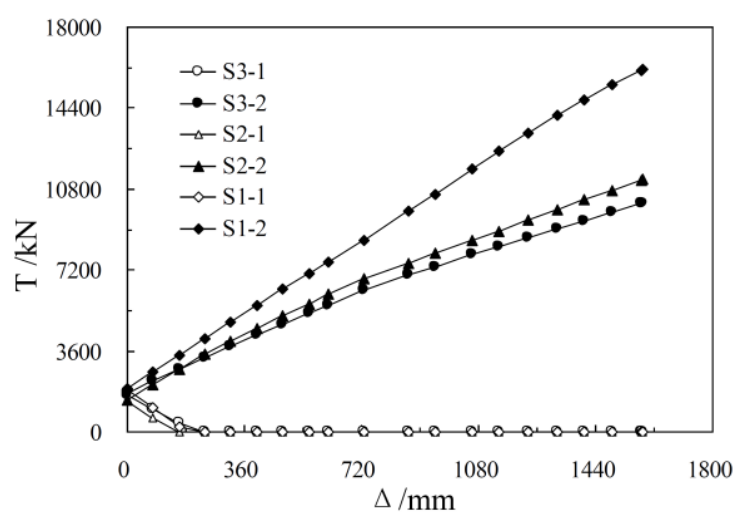

(b) Cables at lower three large layers

Fig. (37). The tension of cables and roof displacement under the horizontal load of uniform distribution. 
structure gradually reduces and the lateral stiffness derived from Pushover under the inverse triangular distribution is less than that under the uniform distribution, the former elastic lateral rigidity is $27.1 \mathrm{kN} / \mathrm{mm}$ and the latter is 38.8 $\mathrm{kN} / \mathrm{mm}$.

\subsection{Prestressed Cable}

The curve of cable tension in each large layer and displacement at the top of structure under the horizontal load of inverse triangle distribution is shown in Fig. (36). A symbol of S6-1 represents the cable at left of 6th large layer and S6-2 represents the cable at right of 6th large layer in figure. The other symbols are similar to these two meanings. When the displacement at top is $159 \mathrm{~mm}$, the tensions of cables with symbol of S2-1 begin to reduce the zero at first and these cables quit working. When the roof displacement reaches $888 \mathrm{~mm}$, all the cables with symbol of number "1" are out of working and the cables of S6-1 stop working in the end last. However, the increased speeds of tension in each large layer are different for the cables with symbol of number " 2 " because the slopes of curve for the tension of cables are different from each other and the increment of tension for the cables at top large layer is slowest. As a whole, the cable quits working sooner and the increased speed of tension for another cable at the same layer is faster.

The curve of cable tensiossssn in each large layer and roof displacement under the horizontal load of uniform distribution is shown in Fig. (37). On the whole, it can be seen from this figure that the change of tension for cables is similar to that under the horizontal load of inverse triangle distribution. But the time is later when the last group of
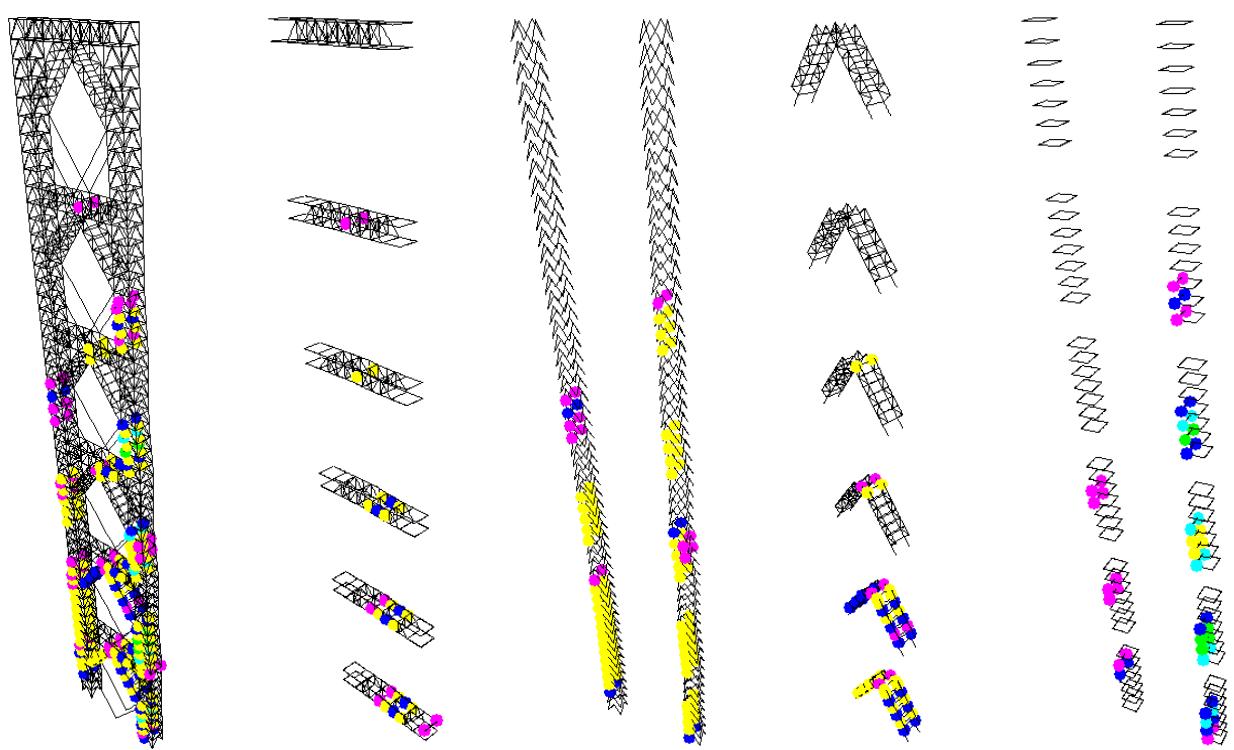

(a) whole (b) mega beams (c) braces between mega column limbs (d) mega $\Lambda$-shape steel bracing truss (e) floor beams between mega column limbs

Fig. (38). Plastic hinges under the horizontal load of inverse triangular distribution at the ultimate bearing capacity.
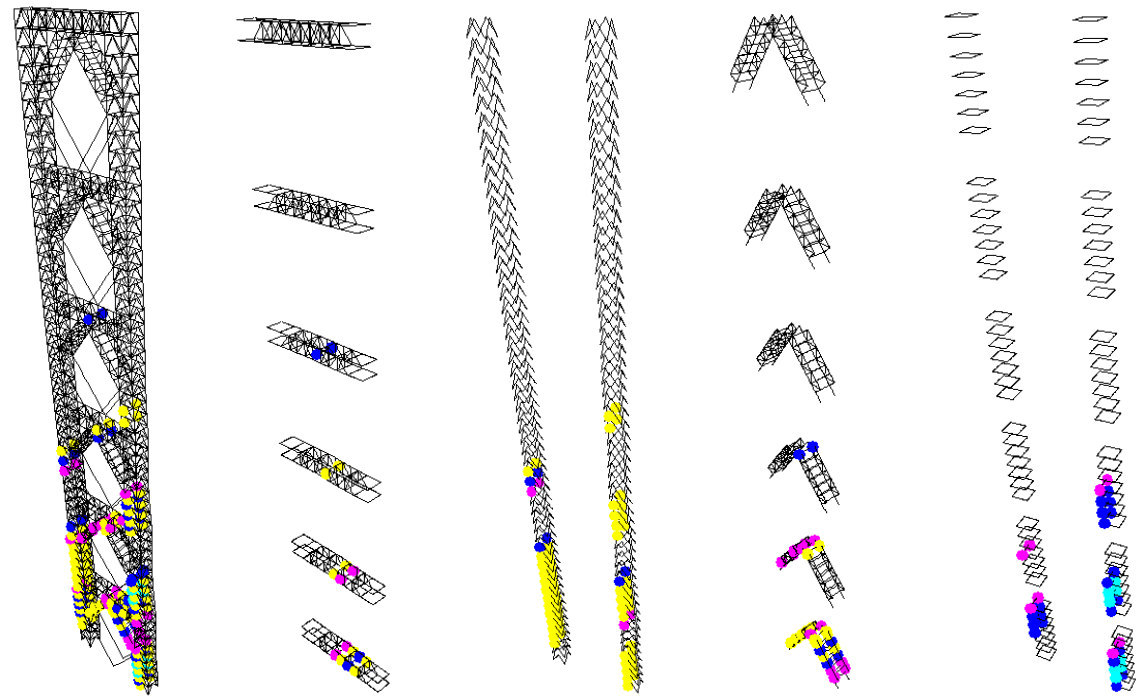

(a) whole (b) giant beams (c) braces between mega column limbs (d) mega $\Lambda$-shape steel bracing truss (e) floor beams between mega column limbs

Fig. (39). Plastic hinges under the horizontal load of uniform distribution at the ultimate bearing capacity. 
cables quit working and the increased speed of tension is also slower.

\subsection{Failure Mode of Structure [20]}

(1) The horizontal load of inverse triangular distribution.

When the horizontal load of inverse triangular distribution is up to limit state of $38714 \mathrm{kN}$, the displacement at top is $2160 \mathrm{~mm}$ and then a lot of plastic hinges occur at the structure.

With the increase of horizontal load, the destruction of this structural system gradually develops from bottom to upper layer under the horizontal load of inverted triangular distribution mode. The yielding order of all members is as follows: the web members of giant beam yield at first, and then the braces between the giant column limbs, giant $\Lambda$ shape steel bracing truss and floor beams between the giant column limbs in order. The plastic development occurred at the system is quite well when this structure reaches the ultimate state under the horizontal load. The plastic degree of braces between the giant column limbs, giant beam and giant $\Lambda$-shape steel bracing truss is quite large and many plastic hinges are occurred.

\section{(2) The horizontal load of uniform distribution}

When the horizontal load of uniform distribution is up to limit state of $43007 \mathrm{kN}$, the displacement at the top of structure is $1585 \mathrm{~mm}$ and then many plastic hinges shown in the Fig. (39) occur at the structure.

With the increase of horizontal load, the destruction of structural system under the horizontal load of uniform distribution mode is mainly concentrated at bottom and the middle story. The yielding order of all members is as follows: the web members of giant beam yield at first, and then the braces between the giant column limbs, giant $\Lambda$ shape steel bracing truss and floor beams between the giant column limbs in order.

Compared with Fig. (38 and 39), when structure reaches the horizontal limit state, the number of destroyed storey under the horizontal load of uniform distribution mode is lower than that under the horizontal load of inverted triangular distribution mode. At the same time, the different base shear-top displacement curve, horizontal lateral stiffness and ultimate bearing capacity are obtained under the different horizontal loading mode, but the failure mode of structure is similar.

The giant $\Lambda$-shape steel bracing truss used for the seismic energy dissipation has a large number of plastic hinges and the giant column limb which is the most critical factor for the safety of structure begins to form some plastic hinges after the giant beams and giant $\Lambda$-shape steel bracing truss have plastic hinges, which conforms to the seismic design philosophy of "strong column and weak beam" and "the first seismic fortification line destroys at first".

\section{CONCLUSION}

Considering nonlinear effects of both material and geometry, MFPCBS is studied based on 3-D finite element model. By studying the static performance of whole loading process in the view of deformation and internal force, the seismic performance in the view of energy dissipation and the limit state in the view of failure mode, main conclusions are obtained as follows.

The lateral deformation of MFPCBS is mainly caused by horizontal loads and the displacement characteristic is flexure on the whole, while the bending-shearing deformation characteristic is significant at joint zones.

The mega beam deflection is decided by vertical loads and prestress. The horizontal loads have influence on maximum shear force and bending moment of mega beam, but have no effect on its deflection.

The vertical load variation within $20 \%$ range which obviously affects the deformation and internal forces of mega beam leads to the internal forces of composite bracings in disequilibrium. The internal force increment of rigid brace is greater than that of cable and the degree of disequilibrium is about $15 \%$.

The horizontal load variation within $20 \%$ range almost has no effect on horizontal members. The lateral deformation pattern is unchanged and the horizontal displacement is approximately proportional to the horizontal loads. The internal forces of composite bracings are in equilibrium, which means that the variation of anti-symmetric horizontal loads has no effect on the equilibrium of composite bracings.

Compared with MFS and MTS, the composite bracings in MFPCBS transfer a considerable part of loads on mega beam to mega column, so the deflection and internal force of mega beam are obviously reduced. The composite bracings have also improved the lateral stiffness at the same time. The fluctuation amplitude of storey drift ratio diagram in MFPCBS is relatively much small, which means that the lateral stiffness distribution of MFPCBS is more homogeneous.

MFPCBS under various earthquake waves has excellent seismic performance because of the TMD effect of substructures and the existence of additional dampers. Most of energy is dissipated by dampers and substructures, so main structure is able to maintain elastic.

The two different distribution patterns of lateral loads which are the uniform distribution and the inverse triangle distribution do not affect the yielding order and failure mode of structure, but the relationship between the base shear force and the top horizontal displacement, the lateral structural stiffness and the ultimate load are different under the two different distribution patterns.

The desired failure mode of MFPCBS under lateral loads is as follows: the web members of mega beam appear to yield at first, and then the braces between mega column limbs, $\Lambda$-shape rigid bracing truss, floor beams between mega column limbs and mega column limbs in order.

\section{CONFLICT OF INTEREST}

The authors confirm that this article content has no conflicts of interest. 


\section{ACKNOWLEDGEMENTS}

This research work was sponsored by the National Natural Science Foundation of China (No. 50948035, 51308260) and Natural Science Foundation of Jiangsu Province (No. BK2009723).

\section{REFERENCES}

M. Q. Feng and A. Mita, "Vibration control of tall buildings using mega-sub configuration", J. Eng. Mech., vol. 121, no. 10, pp. 10821087, 1995.

[2] M. Q. Feng and W.Chai, "Design of a mega-sub-controlled building system under stochastic wind loads", Probab. Eng. Mech., vol. 12, no. 3, pp. 149-162, 1997.

[3] Y. Zhang, J. Bi, W. Zhang and L. Chen, "Test of spatial hysteresis behavior for mega steel column", World Earthquake Eng., vol. 20, no. 1, pp. 117-121, 2004.

[4] Z. Xunan, W. Dong and J. Jiesheng, "The controlling mechanism and the controlling effectiveness of passive mega-sub-controlledframe subjected to random wind load", J. Sound Vib., vol. 3, no. 28, pp. 543-560, 2005.

[5] Z. Hengjing, "Study on Simplified Models and Aseismic Analysis for Mega-structure, thesis of Master of Philosophy, Tongji University 2006. Shanghai: (in Chinese).

[6] H. Takabatake, T. Satoh, "A simplified analysis and vibration control to super-high-rise building", Struct. Des Tall Spec Build., vol. 15 , no. 4, pp. 363-390, 2006

[7] H. Fan, Q. S. Li, A. Y. Tuan and L. Xu, "Seismic analysis of the world's tallest building", J. Construct. Steel Res., vol. 65, pp. 1206$1215,2009$.

[8] K. S. Moon, "Stiffness-based design methodology for steel braced tube structures: A sustainable approach", Eng. Struct., vol. 32, pp. $3163-3170,2010$
[9] Z. Yun, C. Lin, D. Xuesong and W. Tingyan, "A new structure system: mega braced frame with energy dissipators", J. Guangzhou Univ. (Natural Science Edition), vol. 6, no. 3, pp. 56-61, 2007. (in Chinese)

[10] Y. Lian, X. Zhang and C. Sheldon, "Damping characteristics of friction damped braced frame and its effectiveness in the mega-sub controlled structure system", Earthquake Eng. Vib., vol. 6, no. 2, pp. 171-181, 2007.

[11] T. Baijian and R. Hanting, "Analysis on performance of mega steel frame and prestressed composite brace structure", J. Guangxi Univ., vol. 35, no. 4, pp. 574-581, 2010. (in Chinese)

[12] Building Research Institute. Response and Limit Capacity Calculation [M]. Tokyo: Kougaku-Tosho, 2001. (in Japanese)

[13] N. C. Tsai, "Spectrum-compatible motins for design purpose", ASCE, vol. 98, no. EM2, pp. 345-356,1972.

[14] T. Baijian and Z. Jingjing, "Perfect theoretical equation of optimum initial prestress of stayed steel column", Eng. Mech., vol. 28, no. 9, pp. 143-148, 2011. (in Chinese)

[15] X. Yuan, L. Chen and S. Dong, "Prestress design of cable domes with new forms", Int. J. Solids Struct., vol. 44, pp. 2773-2782, 2007.

[16] H. Krawinkler and G. D. P. K. Seneviratna, "Pros and cons of a pushover analysis of seismic performance evaluation", Eng. Struct., vol. 20, no. 4-6, pp. 452-464, 1998.

[17] A. S. Elnashai, "Advanced inelastic static (pushover) analysis for earthquake applications", Struct. Eng. Mech., vol. 12, no. 1, pp. 5169, 2001.

[18] FEMA 273. NEHRP Guidelines for the Seismic Rehabilitation of Buildings [S]. Washington, D.C. 1997.

[19] ATC-40. Seismic Evaluation and Retrofit of Concrete Buildings [S]. California, 1996

[20] D. Yan and C. C. Chang, "Vulnerablity assessment of single-pylon cable-stayed bridges using plastic limit analysis", Eng. Struct., vol. 32, no. 1, pp. 306-318, 2011 .

Received: October 17, 2012

(C) Baijian et al.; Licensee Bentham Open.

This is an open access article licensed under the terms of the Creative Commons Attribution Non-Commercial License (http://creativecommons.org/licenses/ by-nc/3.0/) which permits unrestricted, non-commercial use, distribution and reproduction in any medium, provided the work is properly cited. 